\title{
System Design and Experimental Research on the Tangential Ultrasonic Vibration-assisted Grinding Gear
}

\section{Wenbo Bie}

Henan Polytechnic University

Bo Zhao ( $\nabla$ zhaob@hpu.edu.cn )

Henan Polytechnic University

Chongyang Zhao

Henan Polytechnic University

Long Yin

Henan Polytechnic University

Xingchen Guo

Henan Polytechnic University

\section{Research Article}

Keywords: Ultrasonic vibration-assisted grinding gear, Longitudinal vibration system, Finite elements analysis, Residual compressive stress, Non-resonant theory

Posted Date: March 24th, 2021

DOI: https://doi.org/10.21203/rs.3.rs-327060/v1

License: (c) (1) This work is licensed under a Creative Commons Attribution 4.0 International License. Read Full License 


\title{
System design and experimental research on the tangential ultrasonic vibration-assisted grinding gear
}

\author{
Wenbo Bie ${ }^{\mathrm{a}, \mathrm{b}}$, Bo Zhao ${ }^{\mathrm{a}, ~ *}$, Chongyang Zhao ${ }^{\mathrm{a}}$, Long Yin ${ }^{\mathrm{a}}$, Xingchen Guo \\ ${ }^{a}$ School of Mechanical and Power Engineering, Henan Polytechnic University, Jiaozuo, Henan, China \\ ${ }^{\mathrm{b} S}$ School of Electrical and Mechanical Engineering, Pingdingshan University, Pingdingshan, Henan, China
}

\begin{abstract}
Gear plays an important role in transmitting motion and power system, and a new promising process should be utilized to enhance the machining accuracy and performance. In this paper, the ultrasonic vibration was superimposed into the gear to carry out the tangential ultrasonic vibration-assisted grinding gear (TUVAGG). The longitudinal resonant vibration system was designed based on the non-resonant theory. Firstly, the gear was simplified into a disc with the diameter of the reference circle, and the dynamic equation of each part was erected respectively. Then the frequency equation was derived according to the coupling conditions of the force and displacement during the combined surface of the vibration system. Simultaneously, the characteristic of displacement for the vibration system was also obtained. Secondly, the vibration system composed of the simplified disc and the gear was simulated by the finite elements analysis method, and verified by the resonant measurement experiment respectively. The measurement results exhibited a good agreement with the theoretical. Finally, the effectiveness of the vibration system was verified through the ultrasonic vibration-assisted grinding gear test. It was found that compared with the conventional grinding gear (CGG), the normal grinding force and tangential grinding force was reduced by $7.4-28.2 \%$ and $8.9-18.9 \%$ respectively during TUVAGG. Besides, the grinding temperature and the surface roughness was declined by 7.6-25.7\% and $8.6-21.8 \%$ respectively, and the residual compressive stress of tooth surface was elevated by 13.2-29.3\%. It was concluded that the non-resonant theory was suitable for the designation of longitudinal vibration system for TUVAGG, and also provided a novel process technology for gear machining.
\end{abstract}

Key words: Ultrasonic vibration-assisted grinding gear; Longitudinal vibration system; Finite elements analysis; Residual compressive stress; Non-resonant theory

${ }^{*}$ Corresponding author Email address: zhaob@hpu.edu.cn 


\section{Introduction}

Gear plays an important role in transmitting motion and power system, and its manufacture presents the comprehensive strength of a country to a certain extent $[1,2]$. With the development of science and technology, gears are widely used in sophisticated equipment, such as high speed transport, aerospace and new energy [3]. Because it is strict with the precision of gear dimensions and performance, the higher requirements for the gear manufacturing technology is put forward. Compared with the conventional machining, ultrasonic machining is beneficial to reduce the cutting force [4], extend tool life [5], enhance machining accuracy [6], improve workpiece surface morphology [7] and increase workpiece wear resistance [8] and corrosion resistance [9]. Thus, the ultrasonic vibration as a novel processing was combined with the conventional gear machining, and some ultrasonic gear machining was developed at home and abroad, such as the ultrasonic vibration-assisted hobbing gear, shaving gear [10], lapping gear [11], honing gear [12] and ultrasonic electrochemical machining gear [13]. Taking the state-of-the-art relevant publications into consideration, the ultrasonic vibration-assisted machining gear could improve the processing technology and manufacturing process, and bring significant variation to the surface integrity and fatigue performance [14]. However, till date, the investigation on the TUVAGG was not found in the publications.

In the TUVAGG, the designation of longitudinal vibration system directly affects the machining effect. It is for the TUVAGG that the gear is not only the workpiece processed, but also the load for the system. In addition, the structure of gear is not determined by the resonant frequency, but by its requirements of application. In the practical application, because the frequency ranges of the ultrasonic vibration system is restricted by the ultrasonic generator, it is impossible to accurately ensure that the frequency of the processed gear is within this range. However, it can be resonated in the frequency range by properly designing the vibration system composed of gear and horn. When designed the ultrasonic honing vibration system with large load, Zhao [15] adopted the local resonance theory to design the system and made the system well resonant by tuning the frequency of ultrasonic generator. On the basis of the four-terminal network method, Wei et al. [16] designed the longitudinal vibration system to grind the steel arc bevel gear with a modulus of $1.25 \mathrm{~mm}$ and a tooth number of 17 , and modified the size of the vibration system through the mass reciprocity method. However, it would increase the error of designation for gears with larger diameter. When conducted the ultrasonic lapping test, $\mathrm{Wu}$ et al. [17] combined the tool and horn as a whole to design, in which the tool was simplified to a small round cone. With the help of the wave equation of variable cross-section along the longitudinal vibration, the continuity conditions of stress and the velocity and the boundary conditions, the frequency equation of the combination was established, and obtained the relationship between the size variation of small bevel gear and the resonant frequency. However, the error of designation was higher due to ignore the effect of section variation in the combination junction surface. Based on the longitudinal vibration wave equation of variable cross-section, Gong et al. [18] simplified the gear into a cylindrical rod and deduced the frequency equation and the amplification coefficient calculation formula. Nevertheless the solution of frequency and amplification coefficient was complicate. Lü et al. [19] took the horn and gear into account and adopted the mass reciprocity method to deal with the mass of the fixed part of the gear, and erected the overall theoretical model for the ultrasonic gear honing. It was found that the designed vibration system could achieve better effect. In all aforementioned researches, the ultrasonic vibration system with larger load was designed during the same material based on the resonant theory. However, this would lead to the designation of vibration system complicate, and be limited by the material of each component. In addition, the effect of gear dimension on the vibrational characteristic (resonant frequency and ultrasonic amplitude) of the vibration system was not considered during the designation. Meanwhile, the 
ultrasonic vibration system for grinding gear was not found in the present publications. Therefore, it is essential to investigate the vibration system for the TUVAGG with different materials.

In order to achieve the designation of longitudinal vibration system for TUVAGG, the theoretical model of the longitudinal vibration system was firstly erected on the basis of non-resonant theory. Then the frequency equation and the displacement characteristics of the longitudinal vibration system were derived from the boundary conditions. The effect of gear dimension on the vibrational characteristics was gained by the finite elements analysis (FEA) method, and analyzed the dynamic characteristics through the numerical method. Then the FEA method was employed to obtain the resonant frequency and ultrasonic amplitude of the vibration system. Besides, the resonant experiment was also conducted to verify the results of theoretical and FEA. Finally, the actual grinding test was conducted to verify the effectiveness of the vibration system.

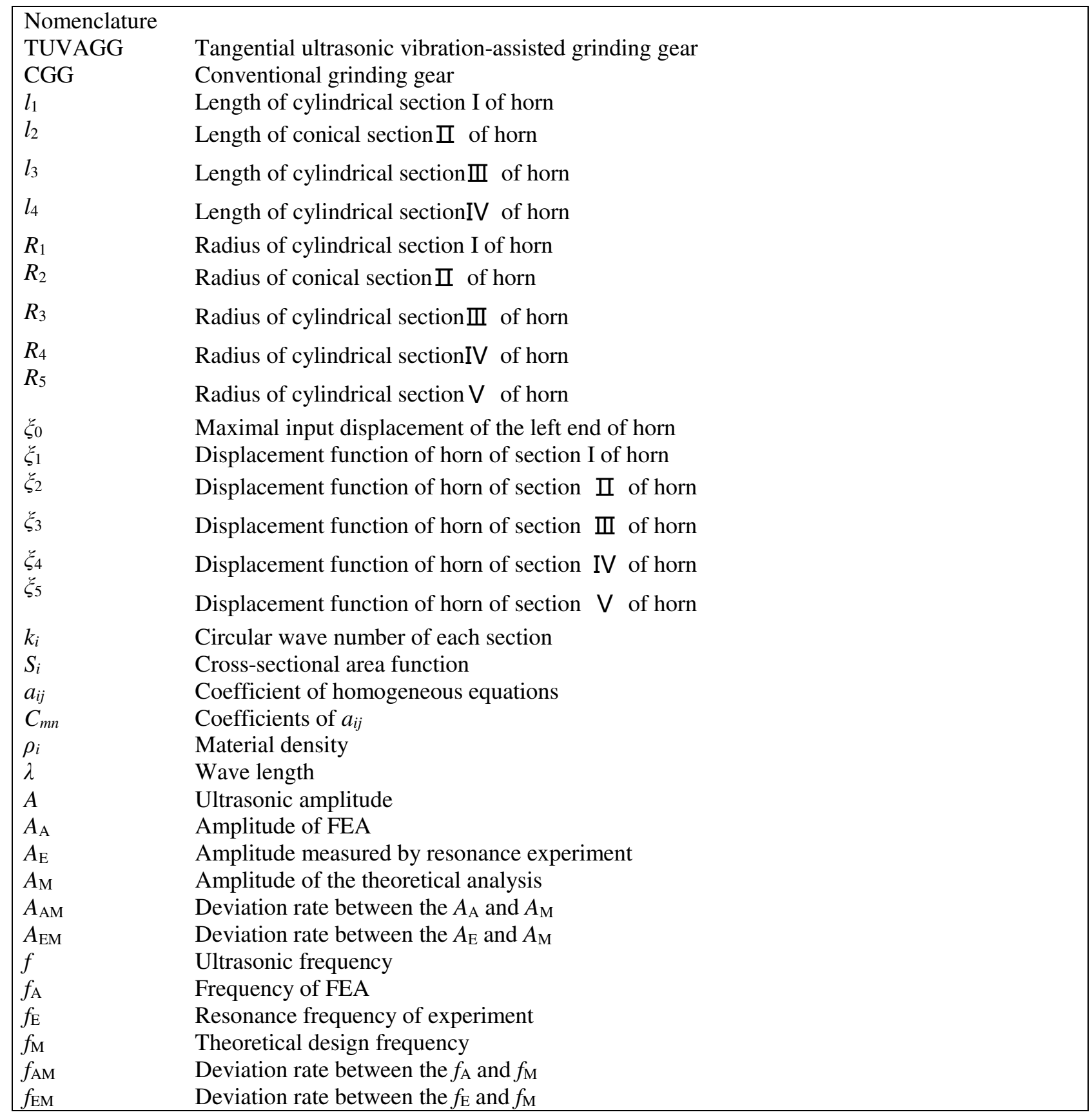

2 Principle of tangential ultrasonic vibration-assisted grinding gear 
The principle of TUVAGG is presented in Fig.1. The experimental apparatus mainly includes machine tool spindle, form-grinding wheel and ultrasonic vibration system. The ultrasonic vibration system primarily consists of an ultrasonic generator, transducer, horn and gear. The ultrasonic generator is used to convert the alternating current into high-frequency electric oscillation. The transducer converted the current of ultrasonic frequency into mechanical vibration for the ultrasonic vibration system. However, the amplitude of mechanical vibration produced by the transducer is too low to be considered for the mechanical machining. Therefore, the horn as a concentrator is added to amplify the ultrasonic vibrational amplitude to applicable magnitude, and drive the gear longitudinal vibration along the tangential direction of grinding wheel. The form-grinding wheel is utilized to machining the gear, so as to realize the tangential ultrasonic vibration-assisted grinding.

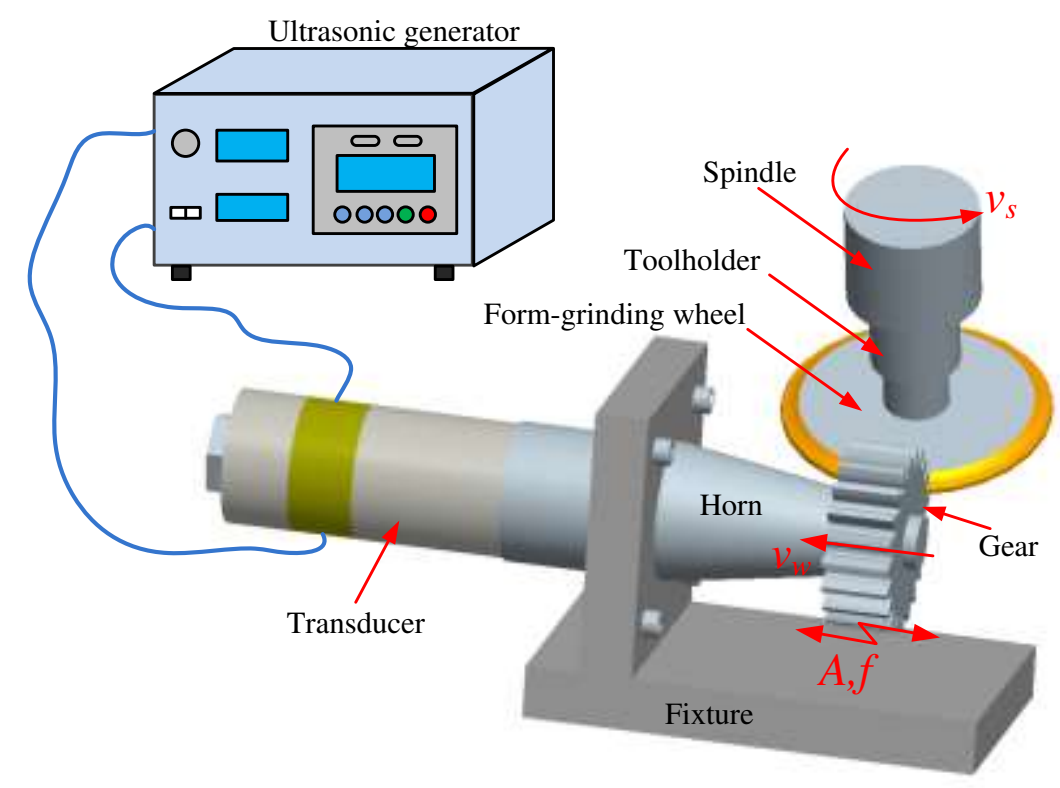

Fig.1. Schematic of tangential ultrasonic vibration-assisted grinding gear

\section{Model of longitudinal resonance system}

For the vibration system of TUVAGG, the gear has a great effect on the vibrational characteristics, and the resonant design theory is not suitable for the designation of vibration system, while the non-resonant theory is more appropriate. The vibration system composed of the gear and horn is firstly regarded as a whole, and the frequency equation is established through the continuous and boundary conditions. Then the frequency is resonant with the working frequency by adjusting the size of the horn. Finally, the resonant frequency and vibration modal is obtained to match the operation.

Generally, the transducer is regarded as the input end of energy during the designation of the vibration system, and its designation of the system is not considered in this study. In order to acquire the higher amplification coefficient, the horn is designed as the composite horn. Considering to facilitating the designation of the vibration system, the assumptions are made as follows [20]:

(1) The vibration system is simplified as a rigid structure, and the contact relationship between the horn, gear and nut is ignored.

(2) The gear is simplified as a cylinder of equal diameter to the reference circle, and the effect of gear shape on longitudinal vibration is neglected.

As presented in Fig.2, the vibration system is mainly consisted of four components, including the transducer, horn, gear and nut. The gear is installed on the small end of the horn and fixed with a nut, and the xoy coordinate system is 
erected in the center of the large end of the horn. The vibration system is composed of five sections, including cylindrical section I, conical section II and cylindrical section III, IV, V respectively, and corresponding length is $l_{1}, l_{2}, l_{3}$ and $l_{4}$. The radius of each section is $R_{1}, R_{2}, R_{3}, R_{4}$ and $R_{5}$ respectively.

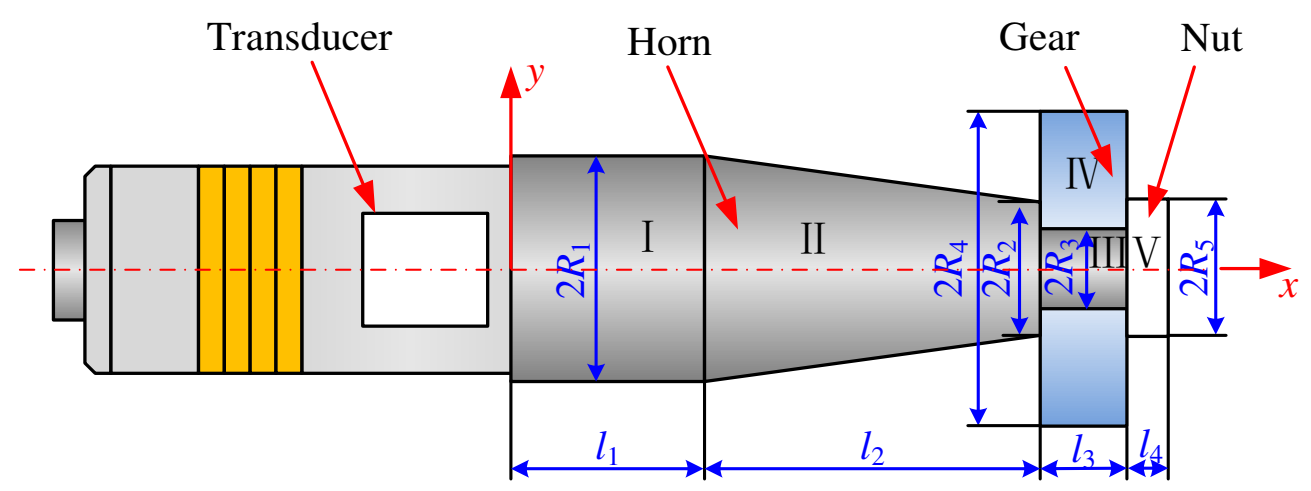

Fig.2. Longitudinal vibration system of TUVAGG

\subsection{Model of the longitudinal vibration system}

In the longitudinal resonance system, it is supposed that a homogeneous and isotropic material is utilized to fabricate the composite horn, and the influence of mechanical loss and damping are neglected. According to the wave equation for the variable cross section [21]:

$$
\frac{\partial^{2} \xi_{i}}{\partial x_{i}^{2}}+\frac{1}{S_{i}} \frac{\partial \xi_{i}}{\partial x_{i}} \frac{\partial \xi_{i}}{\partial x_{i}}+k_{i}^{2} \xi_{i}=0(1)
$$

where $i=1,2,3,4,5$ denotes the segment of I, II, III, IV, V, respectively; $\xi_{i}=\xi_{i}\left(x_{i}\right)$ is the displacement function of each segment; $S_{i}=S_{i}\left(x_{i}\right)$ is the cross-sectional area function of the vibration system; $k_{i}$ is circular wavenumber, $k_{i}=\omega / c_{i}, \omega$ is circular frequency, $c_{i}=\sqrt{E_{i} / \rho_{i}}$ is propagation velocity of longitudinal waves, $\rho_{i}$ is material density, $E_{i}$ is Young's Modulus.

Consequently, for the cylindrical section of I, III and V, the displacement function and stress function are as follows:

$$
\left\{\begin{array}{l}
\xi_{i}\left(x_{i}\right)=a_{i 1} \cos k_{i} x_{i}+a_{i 2} \sin k_{i} x_{i} \\
\frac{\partial \xi_{i}}{\partial x_{i}}=-a_{i 1} k_{i} \sin k_{i} x_{i}+a_{i 2} k_{i} \cos k_{i} x_{i}
\end{array}\right.
$$

where $i=1,3,5$ denotes the segment of $\mathrm{I}, \mathrm{III}, \mathrm{V}$, respectively.

For the conical section of II, the displacement function and stress function can be expressed as :

$$
\left\{\begin{array}{l}
\xi_{2}\left(x_{2}\right)=\frac{1}{x_{2}-1 / \alpha}\left(a_{21} \cos k_{2} x_{2}+a_{22} \sin k_{2} x_{2}\right) \\
\frac{\partial \xi_{2}\left(x_{2}\right)}{\partial x_{2}}=\frac{1}{x_{2}-1 / \alpha}\left(-a_{21} k_{2} \sin k_{2} x_{2}+a_{22} k_{2} \cos k_{2} x_{2}\right)-\frac{1}{\left(x_{2}-1 / \alpha\right)^{2}}\left(a_{21} \cos k_{2} x_{2}+a_{22} \sin k_{2} x_{2}\right)
\end{array}\right.
$$

where $\alpha=\left(R_{1}-R_{2}\right) / R_{1} l_{2}$.

For the section of IV, the displacement function and stress function can be written as : 


$$
\left\{\begin{array}{l}
\xi_{4}\left(x_{4}\right)=\frac{1}{R_{4}-R_{3}}\left(a_{41} \cos k_{4} x_{4}+a_{42} \sin k_{4} x_{4}\right) \\
\frac{\partial \xi_{4}\left(x_{4}\right)}{\partial x_{4}}=\frac{1}{R_{4}-R_{3}}\left(-a_{41} k_{4} \sin k_{4} x_{4}+a_{42} k_{4} \cos k_{4} x_{4}\right)
\end{array}\right.
$$

When the model of vibration system is vibrated freely along longitudinal direction, the boundary conditions and coupled conditions of force and displacement should be satisfied as follows:

$$
\begin{gathered}
\left\{\begin{array}{l}
\left.\xi_{1}\left(x_{1}\right)\right|_{x_{1}=l_{1}}=\left.\xi_{2}\left(x_{2}\right)\right|_{x_{2}=l_{1}} \\
\left.\xi_{2}\left(x_{2}\right)\right|_{x_{2}=l_{1}+l_{2}}=\left.\xi_{3}\left(x_{3}\right)\right|_{x_{3}=l_{1}+l_{2}}=\left.\xi_{4}\left(x_{4}\right)\right|_{x_{4}=l_{1}+l_{2}} \\
\left.\xi_{3}\left(x_{3}\right)\right|_{x_{3}=l_{1}+l_{2}+l_{3}}=\left.\xi_{4}\left(x_{4}\right)\right|_{x_{4}=l_{1}+l_{2}+l_{3}}=\left.\xi_{5}\left(x_{5}\right)\right|_{x_{5}=l_{1}+l_{2}+l_{3}}
\end{array}\right. \\
\left\{\begin{array}{l}
\left.E_{1} \pi R_{1}^{2} \frac{\partial \xi_{1}\left(x_{1}\right)}{\partial x_{1}}\right|_{x_{1}=l_{1}}=\left.E_{2} \pi R_{2}^{2} \frac{\partial \xi_{2}\left(x_{2}\right)}{\partial x_{2}}\right|_{x_{2}=l_{1}} \\
\left.E_{2} \pi R_{2}^{2} \frac{\partial \xi_{2}\left(x_{2}\right)}{\partial x_{2}}\right|_{x_{2}=l_{1}+l_{2}}=\left.E_{3} \pi R_{3}^{2} \frac{\partial \xi_{3}\left(x_{3}\right)}{\partial x_{3}}\right|_{x_{3}=l_{1}+l_{2}}+\left.E_{4} \pi\left(R_{4}^{2}-R_{3}^{2}\right) \frac{\partial \xi_{4}\left(x_{4}\right)}{\partial x_{4}}\right|_{x_{4}=l_{1}+l_{2}} \\
\left.E_{5} \pi R_{5}^{2} \frac{\partial \xi_{5}\left(x_{5}\right)}{\partial x_{5}}\right|_{x_{5}=l_{1}+l_{2}+l_{3}}=\left.E_{1} \pi R_{3}^{2} \frac{\partial \xi_{3}\left(x_{3}\right)}{\partial x_{3}}\right|_{x_{3}=l_{1}+l_{2}+l_{3}}+\left.E_{2} \pi\left(R_{4}^{2}-R_{3}^{2}\right) \frac{\partial \xi_{4}\left(x_{4}\right)}{\partial x_{4}}\right|_{x_{4}=l_{1}+l_{2}+l_{3}}
\end{array}\right.
\end{gathered}
$$

In addition, it is for the left end and right end of the vibration system, the boundary condition is given as follows.

$$
\left\{\begin{array}{l}
\left.\frac{\partial \xi_{1}\left(x_{1}\right)}{\partial x_{1}}\right|_{x=0}=0 \\
\left.\frac{\partial \xi_{5}\left(x_{5}\right)}{\partial x_{5}}\right|_{x_{5}=l_{1}+l_{2}+l_{3}+l_{4}}=0
\end{array}\right.
$$

The theoretical model of the vibration system can be obtained through combining Eqs. (5) to (7), and which is composed of an intricate transcendental equation.

\subsection{Frequency equation of longitudinal vibration system}

The homogeneous equations composed of the coefficient of $a_{i j}$ can be obtained through substituting the Eqs. (2) to (4) into Eqs. (5) to (7), respectively. In order for the system to have non-zero solutions, as shown in Eq. (8), the determinant of the system coefficients should be equal to zero. Meanwhile, the equation (8) denotes the frequency equation for the UVAFGG system.

$$
\Delta=\left|\begin{array}{cccccccccc}
C_{11} & C_{12} & 0 & 0 & 0 & 0 & 0 & 0 & 0 & 0 \\
C_{21} & C_{22} & C_{23} & C_{24} & 0 & 0 & 0 & 0 & 0 & 0 \\
C_{31} & C_{32} & C_{33} & C_{34} & 0 & 0 & 0 & 0 & 0 & 0 \\
0 & 0 & C_{43} & C_{44} & C_{45} & C_{46} & 0 & 0 & 0 & 0 \\
0 & 0 & C_{53} & C_{54} & 0 & 0 & C_{57} & C_{58} & 0 & 0 \\
0 & 0 & C_{63} & C_{64} & C_{65} & C_{66} & C_{67} & C_{68} & 0 & 0 \\
0 & 0 & 0 & 0 & C_{75} & C_{76} & C_{77} & C_{78} & 0 & 0 \\
0 & 0 & 0 & 0 & C_{85} & C_{86} & 0 & 0 & C_{89} & C_{810} \\
0 & 0 & 0 & 0 & C_{95} & C_{96} & C_{97} & C_{98} & C_{99} & C_{910} \\
0 & 0 & 0 & 0 & 0 & 0 & 0 & 0 & C_{109} & C_{1010}
\end{array}\right|
$$

where $C_{m n}$ represents the coefficients of $a_{i j}$. 


\subsection{Displacement characteristic of longitudinal vibration system}

In the longitudinal vibration system, it is supposed that the maximal displacement reached at the output end of the transducer.

$$
\left.\xi_{1}\left(x_{1}\right)\right|_{x_{1}=0}=a_{11} \cos k_{1} x_{1}+a_{12} \sin k_{1} x_{1}=\xi_{0}(9)
$$

According to the knowledge of function, the Eqs.(8) and (9) are composed of statically indeterminate Eq.(10). A group of special solution of $C_{m n}$ can be obtained from the Eq.(10), and then substitute them into the displacement function of each section respectively. The longitudinal displacement curve along the $x$ direction can be acquired.

$$
\left(\begin{array}{cccccccccc}
C_{11} & C_{12} & 0 & 0 & 0 & 0 & 0 & 0 & 0 & 0 \\
C_{21} & C_{22} & C_{23} & C_{24} & 0 & 0 & 0 & 0 & 0 & 0 \\
C_{31} & C_{32} & C_{33} & C_{34} & 0 & 0 & 0 & 0 & 0 & 0 \\
0 & 0 & C_{43} & C_{44} & C_{45} & C_{46} & 0 & 0 & 0 & 0 \\
0 & 0 & C_{53} & C_{54} & 0 & 0 & C_{57} & C_{58} & 0 & 0 \\
0 & 0 & C_{63} & C_{64} & C_{65} & C_{66} & C_{67} & C_{68} & 0 & 0 \\
0 & 0 & 0 & 0 & C_{75} & C_{76} & C_{77} & C_{78} & 0 & 0 \\
0 & 0 & 0 & 0 & C_{85} & C_{86} & 0 & 0 & C_{89} & C_{810} \\
0 & 0 & 0 & 0 & C_{95} & C_{96} & C_{97} & C_{98} & C_{99} & C_{910} \\
0 & 0 & 0 & 0 & 0 & 0 & 0 & 0 & C_{109} & C_{1010}
\end{array}\right)^{-1}\left(\begin{array}{l}
\xi_{0} \\
0 \\
0 \\
0 \\
0 \\
0 \\
0 \\
0 \\
0 \\
0
\end{array}\right)=\left(\begin{array}{l}
a_{11} \\
a_{12} \\
a_{21} \\
a_{22} \\
a_{31} \\
a_{32} \\
a_{41} \\
a_{42} \\
a_{51} \\
a_{52}
\end{array}\right)
$$

\section{Design and dynamic analysis of longitudinal resonance system}

\subsection{The effect of gear dimension on the characteristic of vibration system}

It is well known that the length of composite horn would be determined by the load [22]. In order to obtain the influence of the gear dimension on the resonant frequency and the length of horn, the reference radius and its thickness is changed through the FEA method. As shown in Fig.4, when the length of horn and the thickness of gear keep constant, the resonant frequency declines with the increase of the reference radius and the thickness of gear. As the ultrasonic frequency is kept at $20 \mathrm{kHz}$, the horn length decreased with the increase in reference radius, while increased with the thickness.

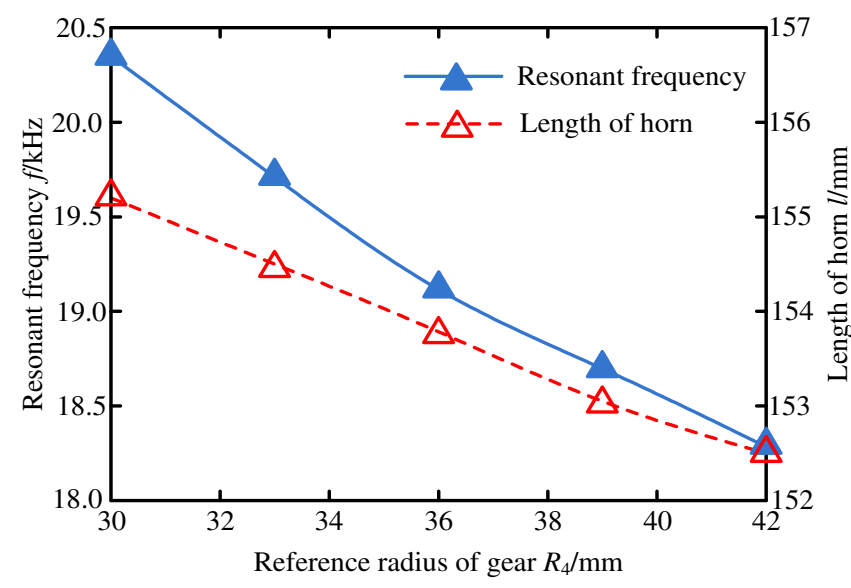

(a)

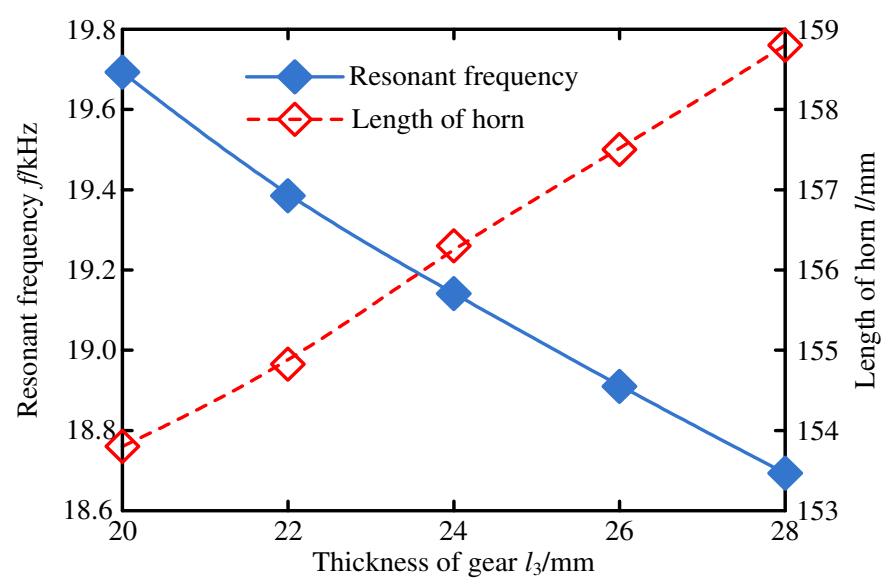

(b)

Fig. 4. Influence of gear dimension on the resonant frequency and horn length (a) Reference radius (b) Thickness

It can be seen from Fig. 4 that the resonant frequency and the horn length are greatly determined by the reference radius and thickness of gear. Compared with reference radius, the thickness has a slight effect on the frequency. When 
the thickness increased and the reference radius decreased, the resonant length $l$ of the horn increased and vice versa, namely $l$ is proportional to the ratio of thickness to diameter of the gear. According to Lü et al. [23], when the diameter of reference circle is lower than $100 \mathrm{~mm}$ and the ratio of thickness to diameter is greater than 0.3 , the longitudinal resonant designation is suitable for the vibration system. As shown in Fig.4, the degree of deviation resonant frequency from the design frequency increases as the reference radius and thickness increasing. Simultaneously, taking the effect of stiffness of the horn into consideration, the gear is selected with a modulus of $3 \mathrm{~mm}$, a number of teeth of 21 and the thickness of $20 \mathrm{~mm}$.

\subsection{Design of the longitudinal vibration system}

The longitudinal vibration system is composed of a disc, horn and nut with different materials. The gear is made of $12 \mathrm{Cr} 2 \mathrm{Ni} 4 \mathrm{~A}$, the horn is $42 \mathrm{CrMo}$ and the nut is $45 \#$ steel. According to Lin [21], the length of the cylindrical section of the composite horn $l_{1}$ should be lower than $\lambda / 4$. It is assumed the length $l_{1}$ is $60 \mathrm{~mm}$, and then the numerical method is utilized to solve the length of the conical section $l_{2}$. Taking the variation range of the length $l_{2}$ as $40-100 \mathrm{~mm}$, the relationship between the value of the determinant of coefficients $\Delta$ and the length of the conical section can be obtained, as shown in Fig.5. Therefore, the length of conical section $l_{2}$ is $65.4 \mathrm{~mm}$.

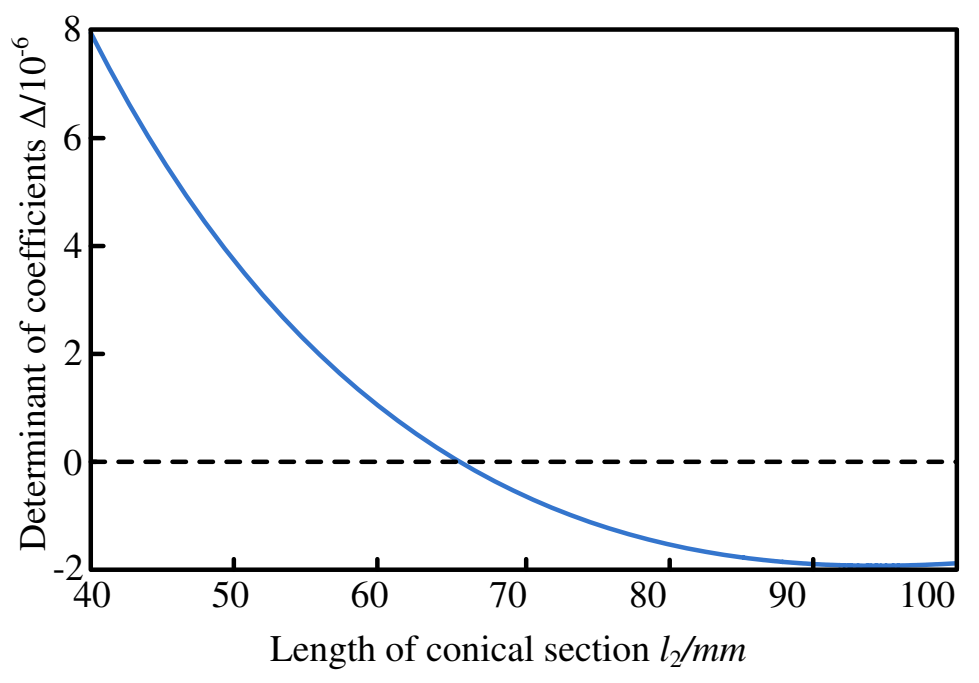

Fig. 5.The solving curve of the conical length of horn

\subsection{Dynamic characteristics of longitudinal resonance system}

It is supposed that the maximum displacement is gained at the output end of the transducer, and the $\xi_{0}$ is equal to $4 \mu \mathrm{m}$. A group of special solution of $C_{m n}$ could be obtained from the Eq.(10), and substitute it into the displacement function of each section respectively. Then as shown in Fig.6, the longitudinal displacement curve could be acquired along the $x$ direction. As depicted in Fig.6, the node position is $58.5 \mathrm{~mm}$ away from the input end of the horn, and the ultrasonic amplitude at the left and right end of the gear is $7.25 \mu \mathrm{m}$ and $7.36 \mu \mathrm{m}$, respectively. 


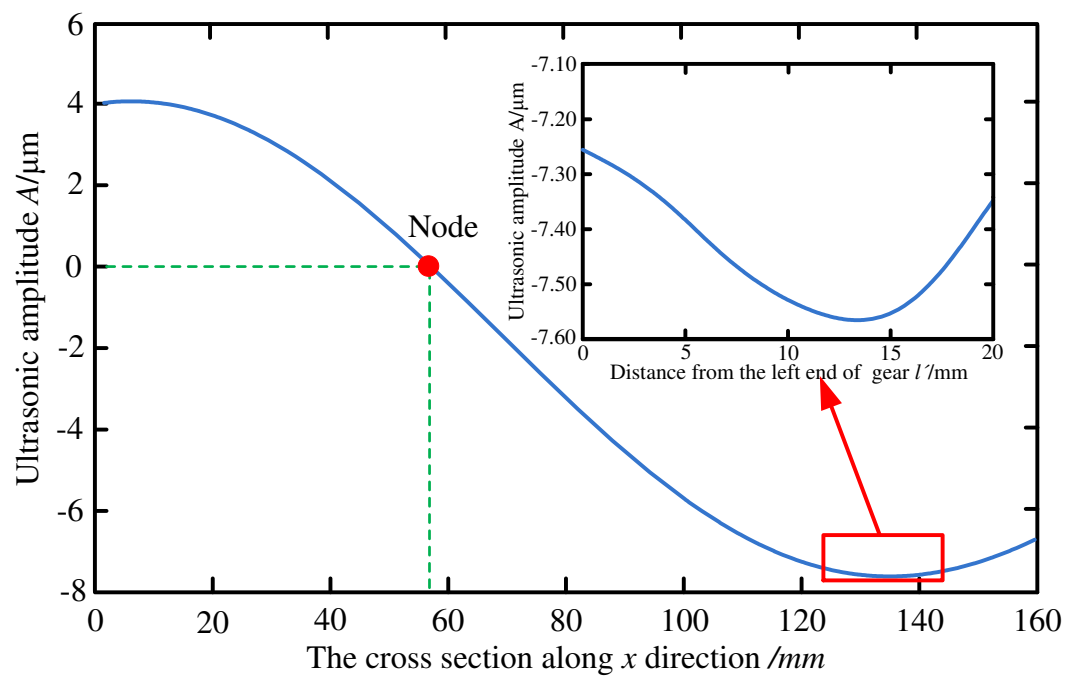

Fig.7.The ultrasonic amplitude along $x$ direction

\subsection{Finite element analysis}

In order to confirm the theoretical results, the vibration system composed of simplified disc (named disc vibration system ) and the vibration system composed of gear (named gear vibration system) were analyzed by the FEA method respectively. The 3D models with flange of the vibration system were erected by the software PROE, and imported into the finite element analysis software ANSYS17.0. The displacement constraint of $4 \mu \mathrm{m}$ was applied on the left end of the horn. The modal of the both vibration systems was shown in Fig.8. The resonant frequency of disc vibration system and gear vibration system was $19.64 \mathrm{kHz}$ and $19.20 \mathrm{kHz}$, respectively. Compared with the design frequency of $20 \mathrm{kHz}$, the error of former reached $1.8 \%$, and the latter was $4.0 \%$.

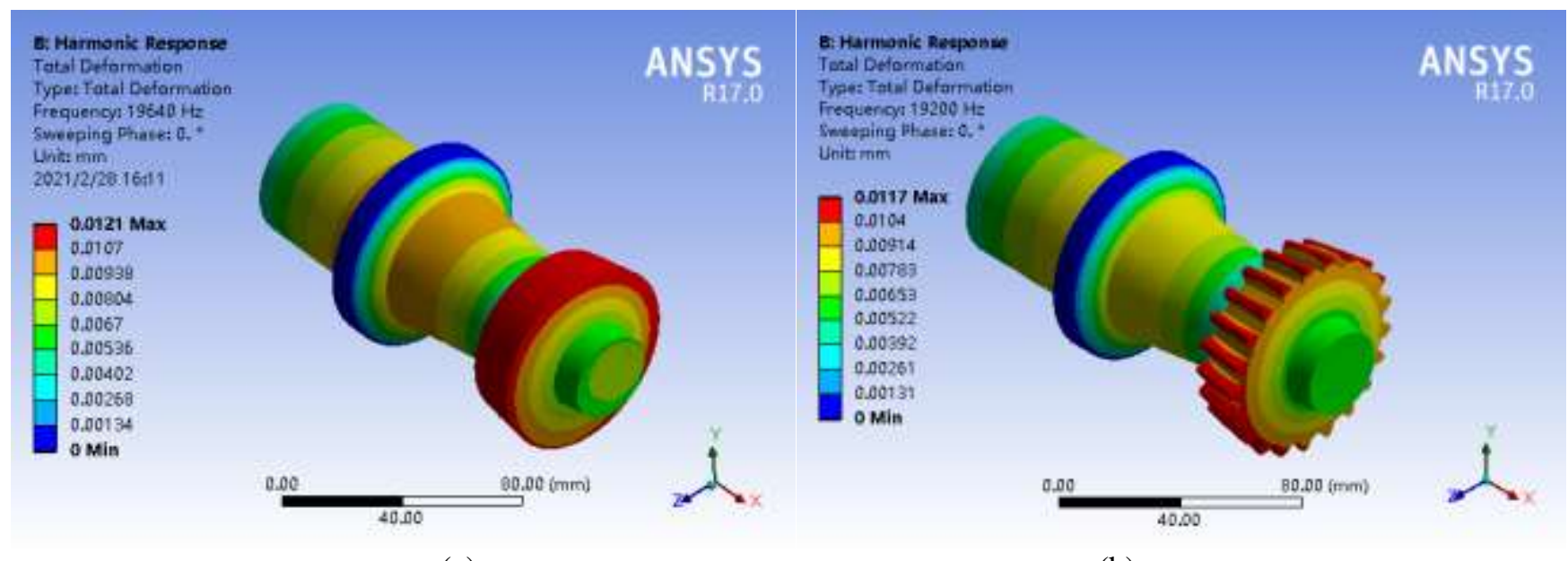

(a)

(b)

Fig.8. Model of longitudinal resonance system (a) Disc vibration system (b) Gear vibration system

The ultrasonic amplitude distribution curves of the vibration system and gear along the $x$ direction were shown in Fig.9. As presented in Fig.9, the ultrasonic amplitude at the left end of disc reached $6.50 \mu \mathrm{m}$ and that of the right end face was $6.76 \mu \mathrm{m}$, and the error reached $10.3 \%$ and $8.2 \%$ compared with the theoretical results. The corresponding ultrasonic amplitude of gear reached $6.62 \mu \mathrm{m}$ and $6.93 \mu \mathrm{m}$, and the error was $8.7 \%$ and $5.8 \%$ respectively. 

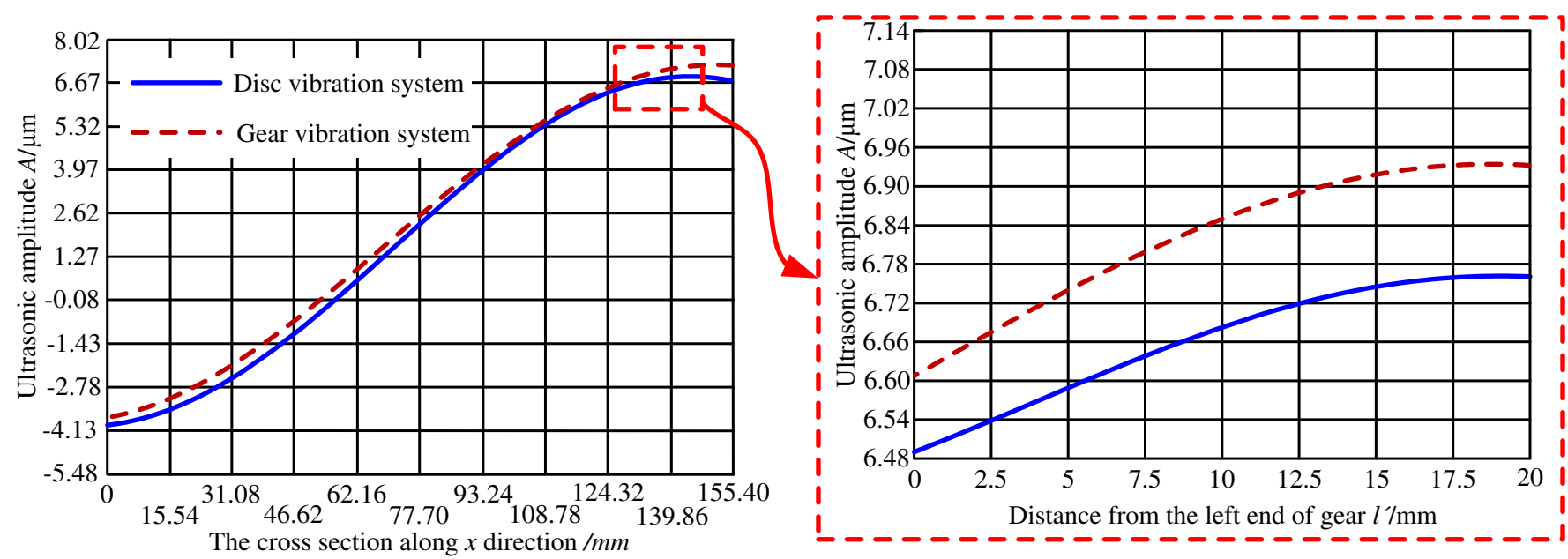

Fig.9. Distribution of ultrasonic amplitude along $x$ direction

\section{Performance test of longitudinal vibration system}

\subsection{Impedance characteristic test}

The components were processed according to the above parameters. In order to reduce energy loss, the bonding surfaces were ground and coated with vaseline before assembled. The Impendance Analyzer PV70 (Beijing Band Era Co. Ltd., China) was utilized to analysis the impedance characteristic of the both vibration system, and the measured results were presented in Fig.10. The resonant frequency of the disc vibration system and gear vibration system was $20.75 \mathrm{kHz}$ and $20.46 \mathrm{kHz}$, respectively, and the corresponding dynamic resistance for the both vibration system was $11.14 \Omega$ and $24.05 \Omega$. As shown in Fig.10, the admittance circle was normal, which meant that the both vibration system achieved the higher quality factor.

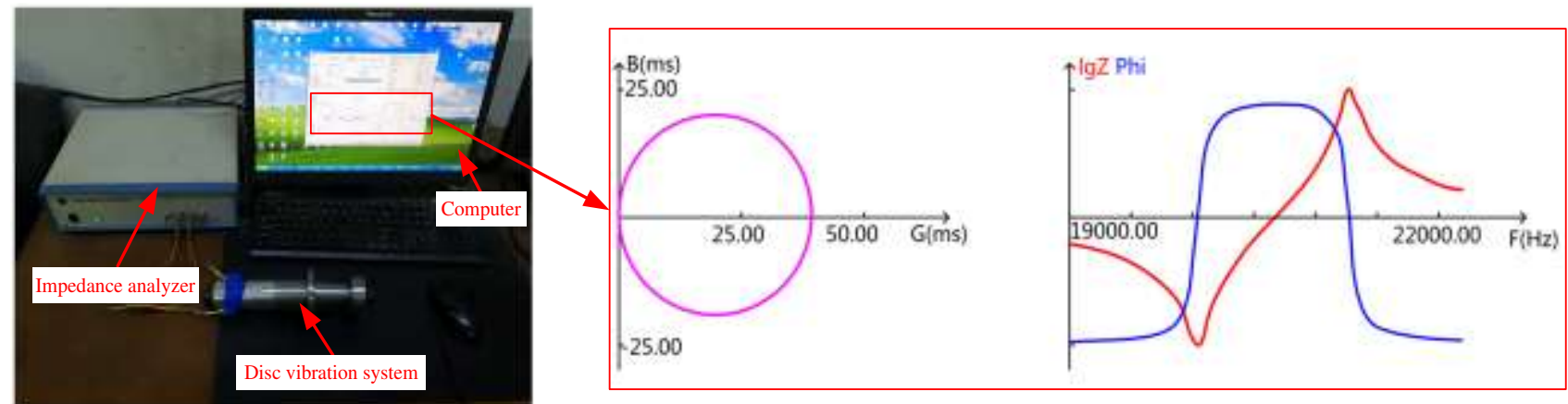

(a)
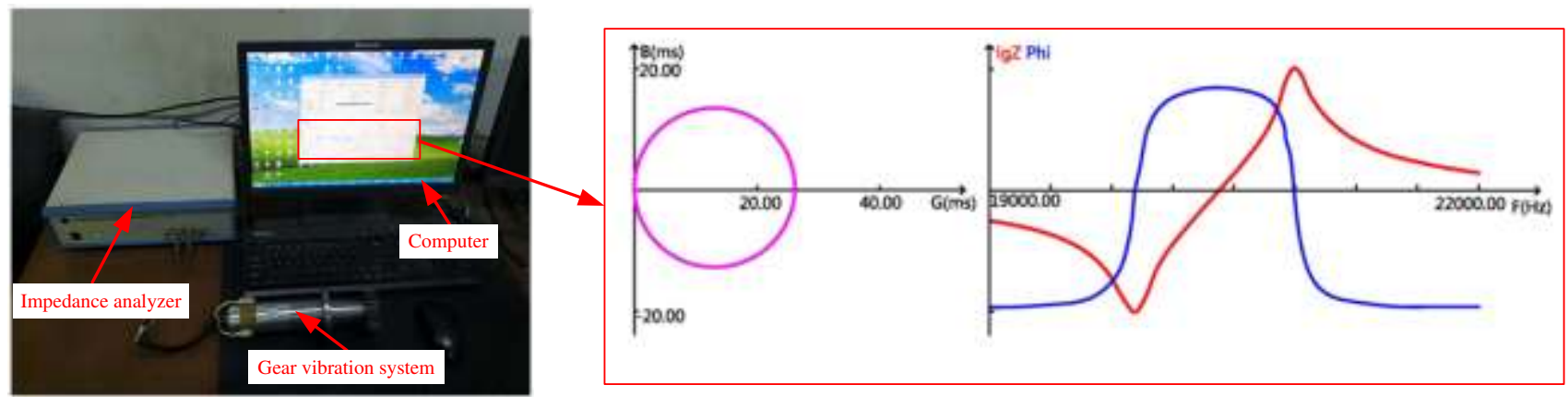

(b)

Fig.10. Impedance test of longitudinal resonance system (a) Disc vibration system (b) Gear vibration system

\subsection{Ultrasonic amplitude test}

The laser displacement sensor (LK-G10,KEYENCE, Japan) was employed to measure the ultrasonic amplitude for the both system. In order to improve the accuracy of measurement, seven measured points were selected at the edge of 
disc (gear). During the measurement of the disc vibration system, the laser beam from the laser displacement sensor was focused on the output end of the disc. The ultrasonic amplitude test of the disc vibration system was presented in Fig.11. When measured the gear vibration system, just take the gear vibration system in Fig.10 (b) replaced the disc vibration system.
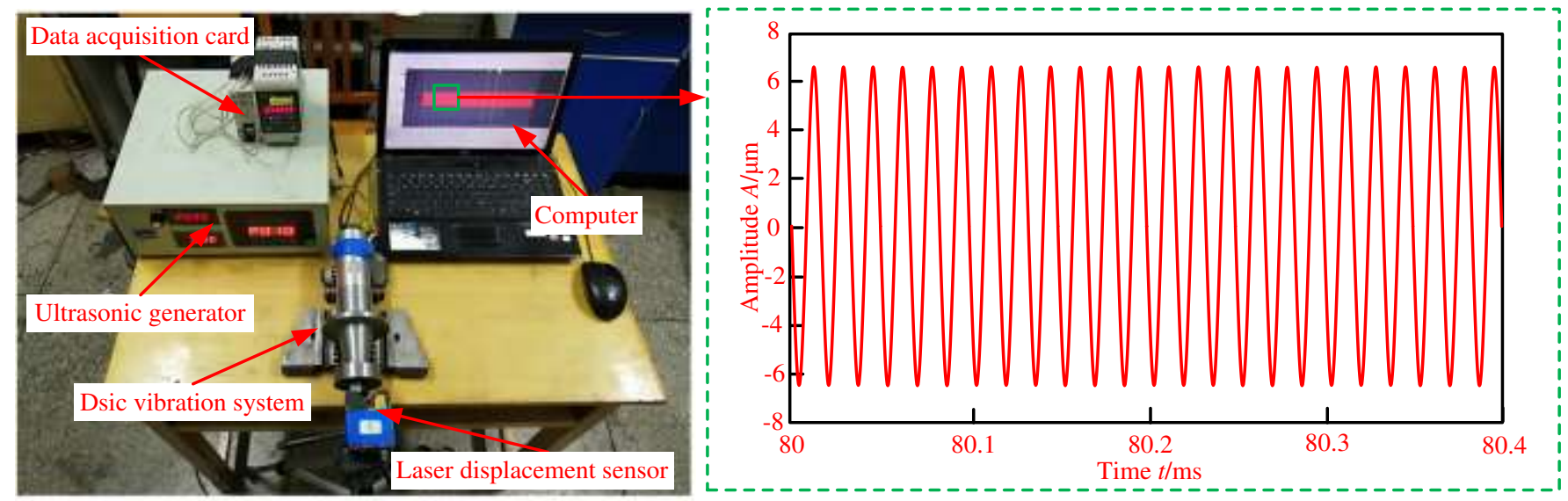

Fig.11.The ultrasonic amplitude measurement of disc vibration system

The results of the both vibration system were presented in Tab.1, where $f_{\mathrm{M}}$ denoted the theoretical design frequency, $f_{\mathrm{A}}$ denoted the frequency of FEA, $f_{\mathrm{E}}$ denoted the resonance frequency of experiment, $f_{\mathrm{AM}}$ represented the deviation rate between the $f_{\mathrm{A}}$ and $f_{\mathrm{M}}$, namely $f_{\mathrm{AM}}=\left|f_{\mathrm{A}}-f_{\mathrm{M}}\right| / f_{\mathrm{M}} \times 100 \% ; f_{\mathrm{EM}}$ represented the deviation rate between the $f_{\mathrm{E}}$ and $f_{\mathrm{M}}$, namely $f_{\mathrm{EM}}=\left|f_{\mathrm{E}}-f_{\mathrm{M}}\right| / f_{\mathrm{M}} \times 100 \% . A_{\mathrm{M}}$ denoted the amplitude of the theoretical analysis, $A_{\mathrm{A}}$ denoted the amplitude of FEA, $A_{\mathrm{E}}$ denoted the amplitude measured by resonance experiment, $A_{\mathrm{AM}}$ represented the deviation rate between the $A_{\mathrm{A}}$ and $A_{\mathrm{M}}$, namely $A_{\mathrm{AM}}=\left|A_{\mathrm{A}}-A_{\mathrm{M}}\right| / A_{\mathrm{M}} \times 100 \%$; $A_{\mathrm{EM}}$ represented the deviation rate between the $A_{\mathrm{E}}$ and $A_{\mathrm{M}}$, namely $A_{\mathrm{EM}}=\left|A_{\mathrm{E}}-A_{\mathrm{M}}\right| / A_{\mathrm{M}} \times 100 \%$. It was observed from Tab.1 that there was a deviation between the measured results and the simulation results, which mainly result from the variation of material. In the FEA, the definition of material was relatively uniform, however, the local material was removed in actual fabrication. The $f_{\mathrm{AM}}$ and $f_{\mathrm{EM}}$ of the both vibration system were lower than $10 \%$, as well as the $A_{\mathrm{AM}}$ and $A_{\mathrm{EM}}$. It was revealed that experimental results concurred with the results of theoretical analysis and FEA.

Tab.1 Test results of the vibration system

\begin{tabular}{ccccccccccc}
\hline Parameters & $f_{\mathrm{M}} / \mathrm{kHz}$ & $f_{\mathrm{A}} / \mathrm{kHz}$ & $f_{\mathrm{E}} / \mathrm{kHz}$ & $f_{\mathrm{AM}} / \%$ & $f_{\mathrm{EM}} / \%$ & $A_{\mathrm{M}} / \mu \mathrm{m}$ & $A_{\mathrm{A}} / \mu \mathrm{m}$ & $A_{\mathrm{E}} / \mu \mathrm{m}$ & $A_{\mathrm{AM}} / \%$ & $A_{\mathrm{EM}} / \%$ \\
\hline Disc vibration system & 20 & 19.64 & 20.75 & 1.8 & 3.75 & 7.36 & 6.76 & 6.67 & 8.20 & 9.38 \\
Gear vibration system & 20 & 19.20 & 20.46 & 4.0 & 2.30 & 7.36 & 6.93 & 6.84 & 5.80 & 7.07 \\
\hline
\end{tabular}

\section{Ultrasonic vibration-assisted grinding gear test}

\subsection{Experimental setup and methodology}

A modified CNC machine center (VMC850E, SMTCL, China) was adopted to perform the UVAFGG test, and the primary experiment setup was presented in Fig.12. It was leadingly composed of the ultrasonic vibration system which was shown in Fig.1, the grinding force acquisition system and grinding temperature acquisition system. The gear vibration system was fixed to the fixture through the flange with four bolts. Then the ultrasonic vibration system was connected with the dynamometer (9257B, Kistler Instrument Corp., Switzerland) through a fixture. The dynamometer was fixe on the workbench with a clamp. 


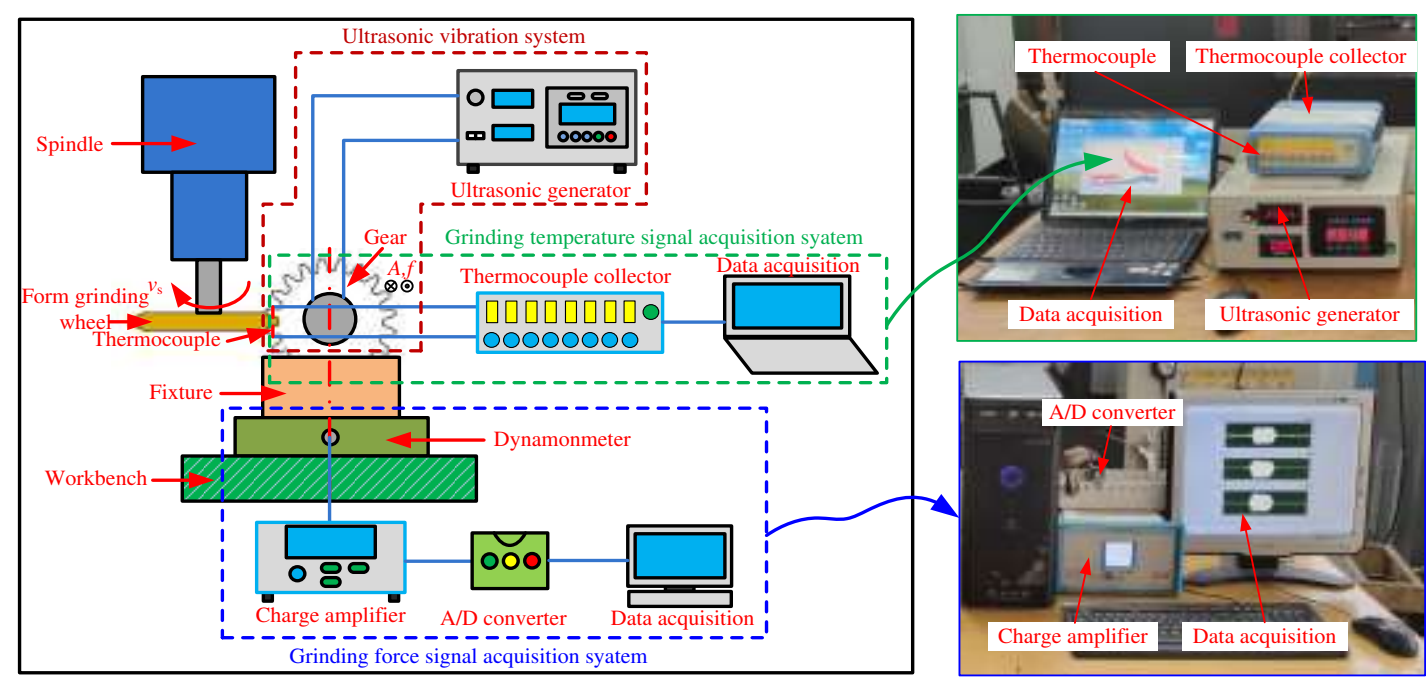

Fig.12. Experimental setup of TUVAGG

An amplifier (5070A) was used to amplify the electrical signal from the dynamometer, and then transmit to a data collector (2825A). A commercial and professional software (Dyno Ware) was employed to save and display the recorded data on a computer.

The thermocouple method was handled to measure the grinding temperature. Two blind holes with the diameter of $1 \mathrm{~mm}$ were prefabricated in the reference circle, and kept $0.2 \mathrm{~mm}$ away from the gear surface. Two K-type thermocouples were placed in the two blind holes respectively, and contacted the end of the hole, in which the plasticine was filled with the opening of hole to fix the thermocouple. During the experiment, the signals from the thermocouples were gathered through a digital thermometer.

In the experiment, the TUVAGG and CGG were achieved by switching on or off the ultrasonic generator. The experimental parameters were presented in Tab.2. Each group parameter was replicated three times, and averaged the above results as the final value. After the TUVAGG experiment, the machined gear teeth were cut using wire-electrode cutting to observe the state of the surface residual stress and surface topography. The surface residual stress was explored with the PROTO X-ray through the XRD method. The white light interferometer (GT-K, BRUKER, USA) was mainly utilized to measure the 3D surface topography.

Tab.2 Experimental parameters

\begin{tabular}{lll}
\hline \multicolumn{1}{c}{ Type } & \multicolumn{1}{c}{ Parameters } & \multicolumn{1}{c}{ Value } \\
\hline \multirow{2}{*}{ Grinding wheel } & CBN form-grinding wheel & 80 \\
& Diameter $D(\mathrm{~mm})$ & 400 \\
& Grinding wheel granularity $(\#)$ & $10,20,30,40$ \\
& Radial grinding depth $a_{r}(\mu \mathrm{m})$ & $1000,2000,3000,4000$ \\
\multirow{2}{*}{ Grinding parameters } & Spindle speed $(\mathrm{r} / \mathrm{min})$ & 400 \\
& Workpiece feed rate $(\mathrm{mm} / \mathrm{min})$ & Without \\
\hline Gear & Coolant & $12 \mathrm{Cr} 2 \mathrm{Ni4A}$ \\
\hline \multirow{2}{*}{ Ultrasonic parameters } & Material & 20.46 \\
& Ultrasonic frequency $f(\mathrm{kHz})$ & 4.8 \\
\hline Methods & Ultrasonic amplitude $A(\mu \mathrm{m})$ & \multicolumn{2}{c}{ TUVAGG, CGG } \\
\hline
\end{tabular}




\subsubsection{Grinding force}

Grinding force is generally employed to evaluate the grinding performance. The relationship between the grinding force and grinding parameters was presented in Fig. 13. It can be seen from Fig.13 that the TUVAGG can significantly reduce the grinding force compared with the CGG, and the normal grinding force and tangential grinding force was reduced by $7.4-28.2 \%$ and $8.9-18.9 \%$, respectively. Furthermore, Figure 13 revealed that the enhancement of the radial grinding depth results in the rise in the grinding force during the both cases, while it declined as the increase of spindle speed. This should be attributed to that the grinding depth of single grain would increase with an increase in radial grinding depth, moreover, the number of effective grain in the grinding zone would increase. However, the length of grinding arc increased during the TUVAGG owing to the trajectory of single grain, which reduce its undeformed chip thickness. Moreover, the surface appeared extremely smooth, and was similar to attach a layer of oil film. It could effectively reduce the friction as the grain cut into the workpiece. Therefore, the grinding force in TUVAGG was reduced by the compressive factors.

As shown in Fig. 13, the maximum reduction ratio of grinding force was obtained in the lower spindle speed. According to Ding et al. [24], when the spindle speed exceed a critical speed, the overlapping and interaction of different grains trajectories were weaken. This would lead to the ultrasonic wave length closer to the trajectory of single grain in the CGG. In other words, the beneficial of ultrasonic vibration was suppressed in the highest spindle speed. Therefore, the grinding force reduction ratio was higher in the lower spindle speed. This result agreed well with that the effective processing at higher spindle speed in CGG could be obtained in lower spindle speed during the TUVAGG, which can also prolong the grinding wheel life.

(a)

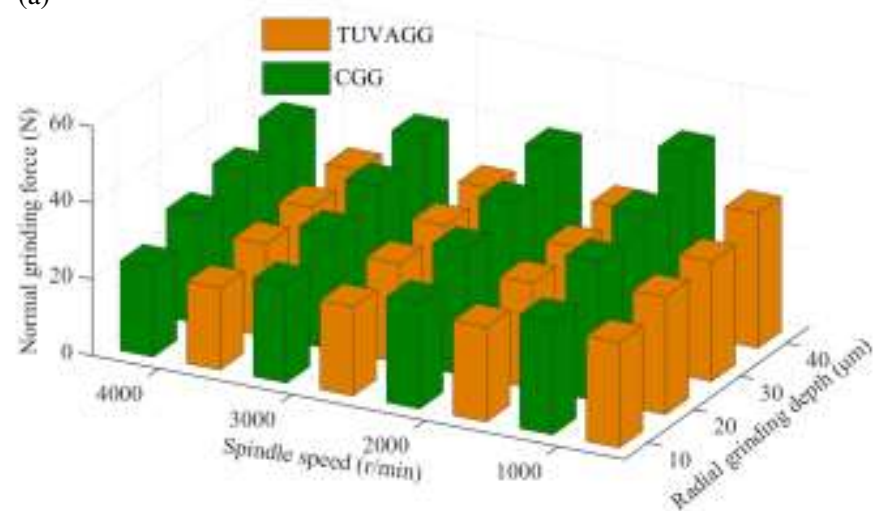

(b)

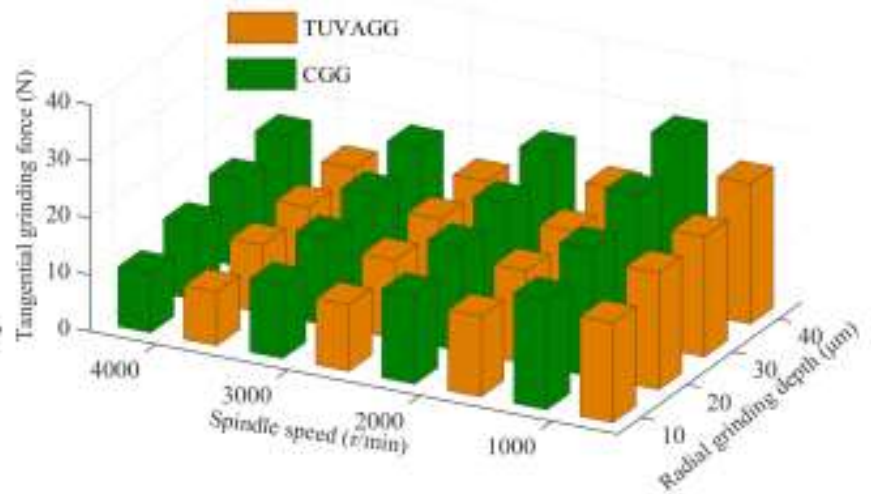

Fig.13. Influence of grinding parameters on the grinding force (a) normal grinding force (b) tangential grinding force

\subsubsection{Grinding temperature}

Grinding temperature is regarded as the key factor influencing the surface quality. Figure 14 presented the relationship between the grinding temperature and grinding parameters. It was observed from Figure 14 that, compared with CGG, the grinding temperature in TUVAGG was significantly reduced by $7.6-25.7 \%$. As the radical grinding depth kept constant, the grinding temperature enhanced with the spindle speed increasing. It was attribute to that the total heat enhanced with the spindle speed, and the heat distribution ratio between grinding wheel and gear also increased. Therefore, the more heat flew to the gear and led to the temperature elevate. When the spindle speed kept constant, an increase of radial grinding depth would cause the grinding temperature enhancement. This resulted from that the contact arc length between the grinding wheel and gear was elongated as the increase of radical grinding depth, and led to the number of grains involved in grinding enhance. Meanwhile, the increasing of undeformed chip thickness resulted in the energy consumption of grinding increase. In addition, the effect of ultrasonic vibration could prompt the grain with 
larger acceleration to impact the workpiece, and the high frequency vibration caused the grains to generate staggered trajectory on its surface, which was propitious to remove the material in smaller energy. Besides, the intermittent grinding conducted between grain and workpiece was conducive to heat dissipation. Consequently, the grinding temperature in TUVAGG was relative lower than that in CGG.

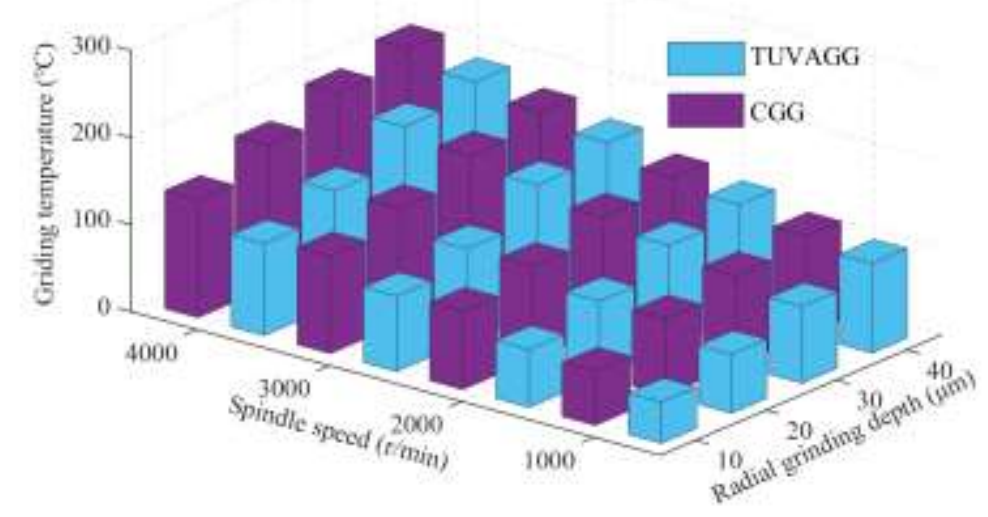

Fig.14 Relationship between the grinding temperature and grinding parameters

\subsubsection{Residual stress}

It was well known that the residual compressive stress could be introduced into the machined surface by adopting appropriate processing technology and adjusting and controlling the input energy, so as to enhance the fatigue resistance and corrosion resistance [25]. Figure 15 presented the trend of residual stress under different parameters, and at the below of the figure, the increasing ratio of residual compressive stress of TUVAGG to CGG was presented. It was found that the tooth surface presented residual compressive stress during both processing. The TUVAGG could enhance the residual compressive stress by 13.2-29.3\% compared with the CGG. In addition, the residual compressive stress decreased with an increase of radial grinding depth and spindle speed. It was leadingly attributed to that the grinding temperature enhanced with an increase of radial grinding depth and spindle speed, and caused the thermal stress to offset the mechanical squeezing effect, and ultimately the residual compressive stress declined. Moreover, when the ultrasonic vibration is superimposed on the gear, the arc length of grain is effectively prolonged, the undeformed chip thickness is reduced and the plastic removal rate of materials is enhanced. It could as well introduce the action of reciprocating ironing and grinding. Meanwhile, the vibrational stress caused by ultrasonic vibration could offset the internal stress and reduce the material's yield strength, so as to improve the residual compressive stress. 


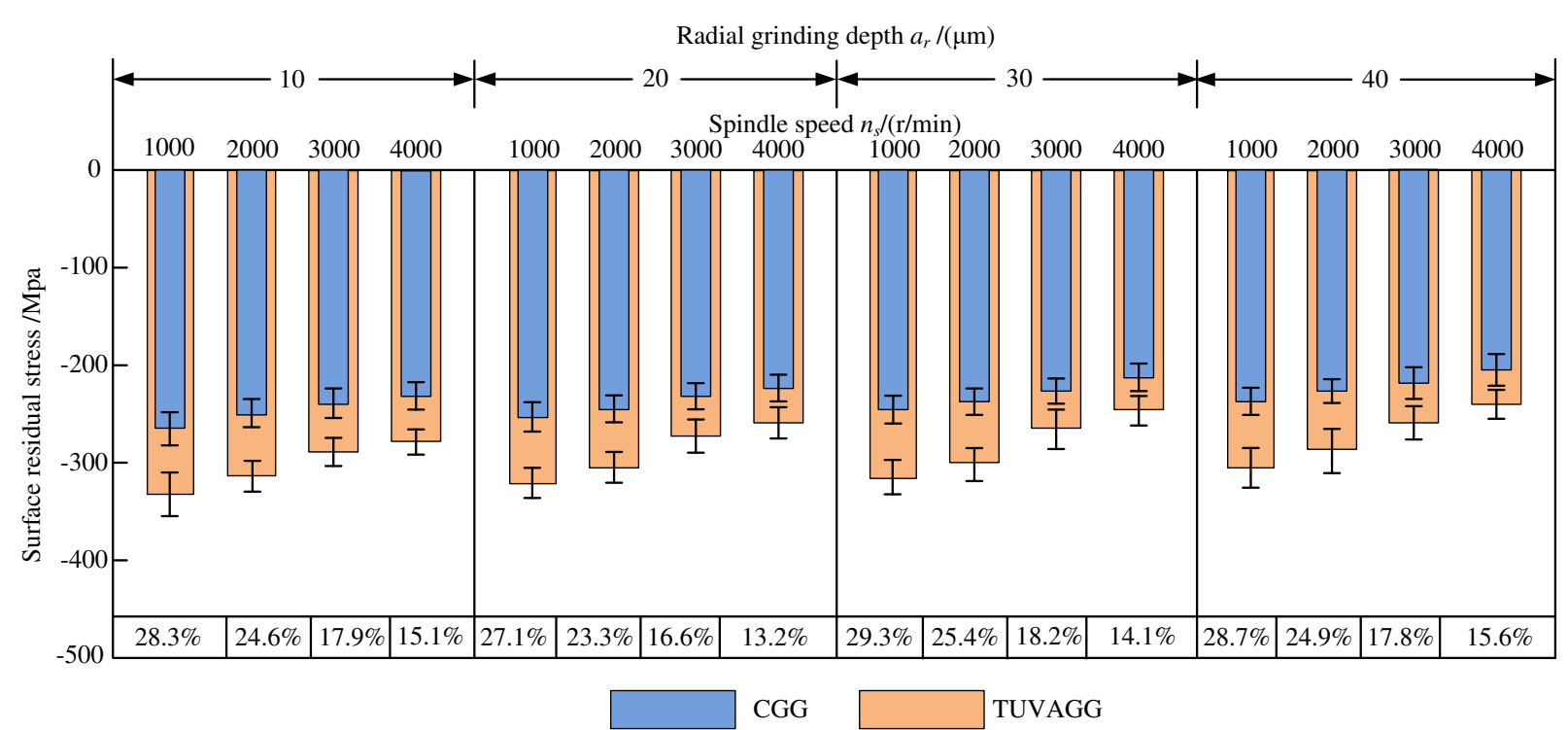

Fig.15. Trend of residual stress on tooth surface

\subsubsection{Surface roughness}

The relationship between the surface roughness and grinding parameters was presented in Fig.16. It was observed from Fig.16 that the surface roughness $R a$ during the TUVAGG was significantly reduced compared with that of CGG. The surface roughness $R a$ can be decreased by $8.6-21.8 \%$ with the variation of spindle speed and radial grinding depth. It was enhanced with the increase of radial grinding depth, while decreased with the spindle speed. This was attributed to that the undeformed chip thickness of a single abrasive grain increased with an increase of radial grinding depth, and caused the plastic-stack on the side of grain obviously. While with the increase of spindle speed, the dynamic abrasive grains participating in grinding increased and led to the undeformed chip thickness decrease. Under the action of tangential ultrasonic vibration, the increased arc length of grain can reduce the undeformed chip thickness to a certain extent, moreover, the grain can be reciprocating ironing and grinding the machined surface. Therefore, the surface roughness was improved during the TUVAGG.

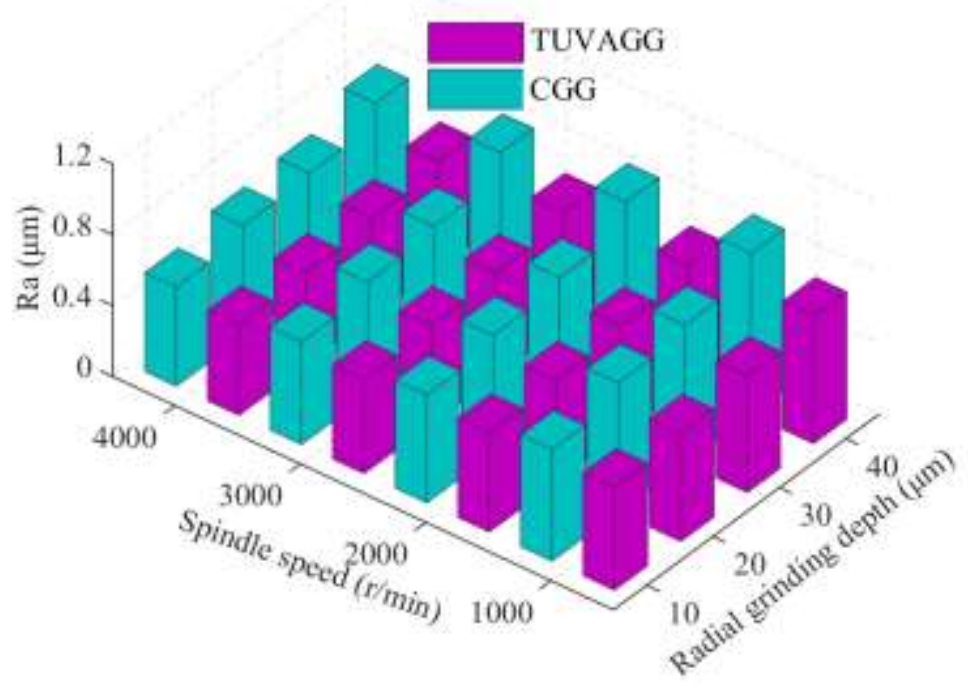

Fig.16. Relationship between the surface roughness and grinding parameters

The gear surface machined by the CGG and TUVAGG were explored through observing the surface texture and microstructure. Figure 17 illustrated the surface topographies of the gear surface in CGG and TUVAGG. The figures 
clearly presented that the gear surface texture during the TUVAGG appeared more flat and smooth. As presented in Fig 17(a), during the CGG, the residual material remained on the surface of the workpiece, and was parallel to grinding direction owing to the gap between the effective grain edges. It resulted in the obvious grooves and ridges on the surface. However, with the help of ultrasonic vibration, the trajectory between grain and workpiece was interfered with each other, and reciprocating impact on the workpiece. This mainly caused the grain to remove the material as small chips. Therefore, as shown in Fig.17 (b) the better surface quality was obtained in TUVAGG.

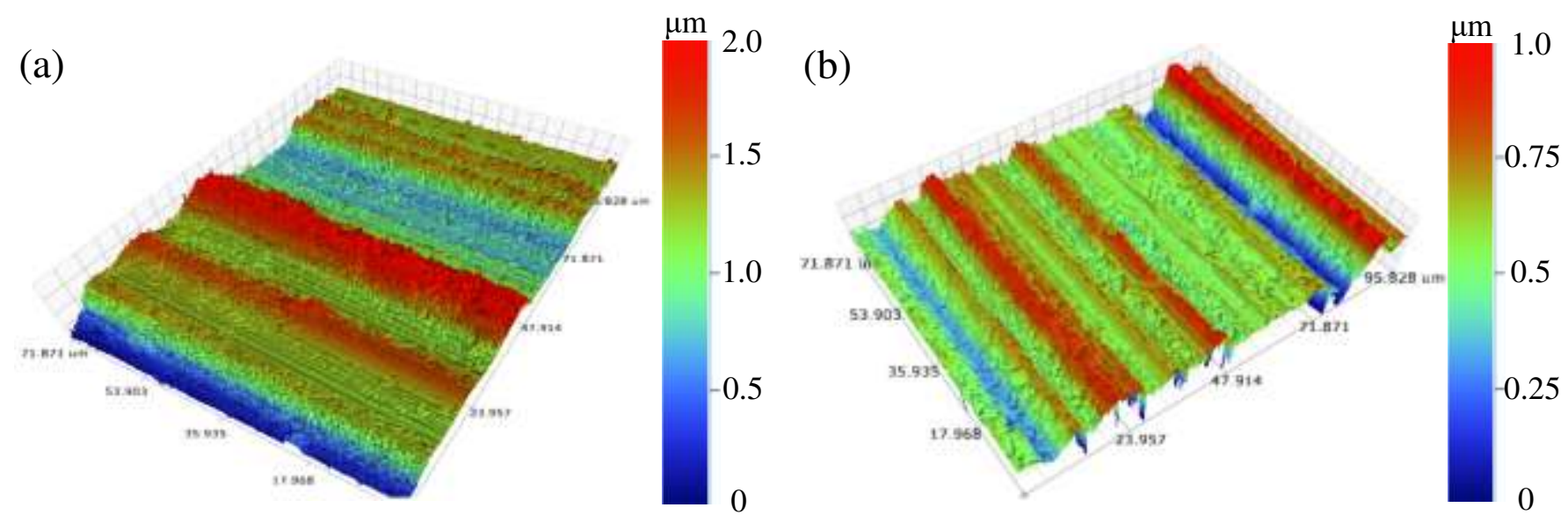

Fig.17 Tooth surface microstructure (a) CGG, (b) TUVAGG

\section{Conclusions}

In this study, the longitudinal vibration system composed of different materials was employed based on non-resonant theory. The FEA method and resonance experiment was conducted and the TUVAGG test was utilized to verify the effectiveness of the designation of the vibration system. According to the findings, the primary conclusions can be obtained as follows.

(1) It was observed that the simplified method for designation of longitudinal gear vibration system was reasonable. The variation of gear dimension for the vibration system played a significant impact on the frequency, and the horn length. The resonant frequency decreases with the increase in the thickness of gear and the reference radius. The length of horn increases with an increase in the thickness and the reference radius decreasing.

(2) From the grinding gear test, compared with the CGG, the normal grinding force and tangential grinding force was reduced by $7.4-28.2 \%$ and $8.9-18.9 \%$ respectively during the TUVAGG. The grinding force reduction ratio in the latter was higher in the lower spindle speed than that in the former. In addition, the effective processing of the higher spindle speed in the CGG could be obtained in lower spindle speed during the TUVAGG. In addition, the grinding temperature in TUVAGG could reduce by $7.6-25.7 \%$ compared with that in CGG.

(3) It was revealed that the ultrasonic vibration could improve the surface residual compressive stress by 13.2-29.3\%, especially in the lower spindle speed. The surface roughness during TUVAGG was reduced by 8.6-21.8\% and the surface texture appeared more flat and smooth, compared with the CGG. In addition, it was the non-resonant theory for the vibration system composed of different materials that could improve the designation precision and generality of the TUVAGG.

\section{Declarations}


Authors' contribution Wenbo Bie conceived the analysis and wrote the manuscript. Bo Zhao provided supervisions on experimentation and manuscript preparation. Chongyang Zhao collected the data and revised the manuscript. Long Yin and Xingchen Guo performed the experiment. The authors discussed each reference paper together and contributed useful ideas for this manuscript.

Funding This work was financially supported by the National Natural Science Foundation of China (Nos. U1604255 and 51905157).

Availability of data and material All data generated or analyzed during this study are included in the present article.

Ethical approval The article follows the guidelines of the Committee on Publication Ethics (COPE) and involves no studies on human or animal subjects.

Consent to participate Not applicable.

Consent to publish Not applicable.

Competing interests The authors declare that no potential conflicts of interest with respect to the research, authorship, and/or publication of this article.

\section{References}

[1] Karpuschewski B, Knoche HJ, Hipke M (2008) Gear finishing by abrasive processes. CIRP Ann Manuf Techn 57 (2): 621-640.

[2] Bie WB, Zhao B, Wang XB, Chen F, Zhang YM (2018) Overview and expectation on gear anti-fatigue manufacture by ultrasonic-assisted machining. Surf Technol 47(7): 35-51.

[3] Gupta K, Jain NK, Laubscher RF (2017) Advanced gear manufacturing and finishing: classical and modern processes, Academic Press, America.

[4] Jiao F, Niu Y, Zhang MJ (2018) Prediction of machining dimension in laser heating and ultrasonic vibration composite assisted cutting of tungsten carbide. J Adv Manuf Syst 17(1): 35-45.

[5] Yu T, Guo X, Wang Z, Xu P, Zhao J (2019) Effects of the ultrasonic vibration field on polishing process of nickel-basedalloy Inconel718. J Mater Process Technol 273: 116228.

[6] Chen HF, Tang JY, Zhou W (2013) An experimental study of the effects of ultrasonic vibration on grinding surface roughness of C45 carbon steel. Int J Adv Manuf Tech 68 (9-12): 2095-2098.

[7] Öpöz TT, Chen X (2012) Experimental investigation of material removal mechanism in single grit grinding. Int J Mach Tools Manuf 63: 32-40.

[8] Kitzig-Frank H, Tawakoli T, Azarhoushang B (2017) Material removal mechanism in ultrasonic-assisted grinding of Al2O3 by single-grain scratch test. Int J Adv Manuf Tech 91: 2949-2962.

[9] Kumar J (2013) Ultrasonic machining-a comprehensive review. Mach Sci Technol 17(3): 325-379.

[10] Kumabe J (1985) The foundation and application of precision vibration cutting. Machinery Industry Press, Beijing.

[11] Wei BY, Deng XZ, Fang ZD (2007) Study on ultrasonic-assisted lapping of gears. Int J Mach Tools Manuf 47(12-13): 2051-2056.

[12] Wang SY, Lü M, Ya G (2008) Research on system design of ultrasonic-assisted honing of gears. Adv Mater Res (53-54): 191-196. 
[13] Singh H, Jain PK (2018) Study on ultrasonic-assisted electrochemical honing of bevel gears. Proc Inst Mech Eng Part B: J Eng Manuf 232 (4SI): 705-712.

[14] Zhao B, Guo XC, Bie WB, Chang BQ, Zhao CY (2020) Thermo-mechanical coupling effect on surface residual stress during ultrasonic vibration-assisted forming grinding gear. J Manuf Processes 59:19-32.

[15] Zhao B (1999) Study on ultrasonic honing system and feature of ductile domain cutting of hard-brittle materials. Ph. D. Thesis, Shanghai Jiao Tong University.

[16] Wei BY, Deng XZ, Yang JJ (2007) Design and experiments of transducer-horn of ultrasonic lapping of gears. Technical Acoustics 26(4): 767-770.

[17] Wu NS, Deng XZ, Yang JJ (2008) Design and study of amplitude transformer horn in the ultrasonic lapping system of hypoid gear. Journal of Mechanical Transmission 32(2): 16-17.

[18] Gong XQ, Xing RF (2009) Design of ultrasonic gear-honing vibration system based on four-terminal network method. New Technology \& New Process. (7): 60-62.

[19] Lü M, She YZ, Qin HB (2013) Design method for a vibration system of ultrasonic gear honing and its dynamic characteristics. J Vib Shock 32(2):147-152.

[20] She YZ, Lü M, Wang SY (2012) Design of transformer with non-resonance structure and its dynamic study. Chin J Mech Eng 48 (7): 49-55.

[21] Lin ZM (1987) Principle and design of ultrasonic horn. Science Press, Beijing.

[22] Wang SY, Lü M, Ya G (2008) Study on dynamical characteristics of transformer with non-resonance annular plate and horn. Acta Acustica 33(5): 462-468.

[23] LüM, Wang SY, Qin HB (2012) Nonresonantdesign theory and ultrasonic gear machining. Science Press, Beijing.

[24] Ding K Fu YC, Su HH, Cui FF, Li QL (2017) Experimental studies on matching performance of grinding and vibration parameters in ultrasonic assisted grinding of SiC ceramics. Int J Adv Manuf Tech 88(9-12): 2527-2535.

[25] Thakur A, Gangopadhyay S (2016) State-of-the-art in surface integrity in machining of nickel-based super alloys. Int J Mach Tools Manuf 100:25-54. 
Figures

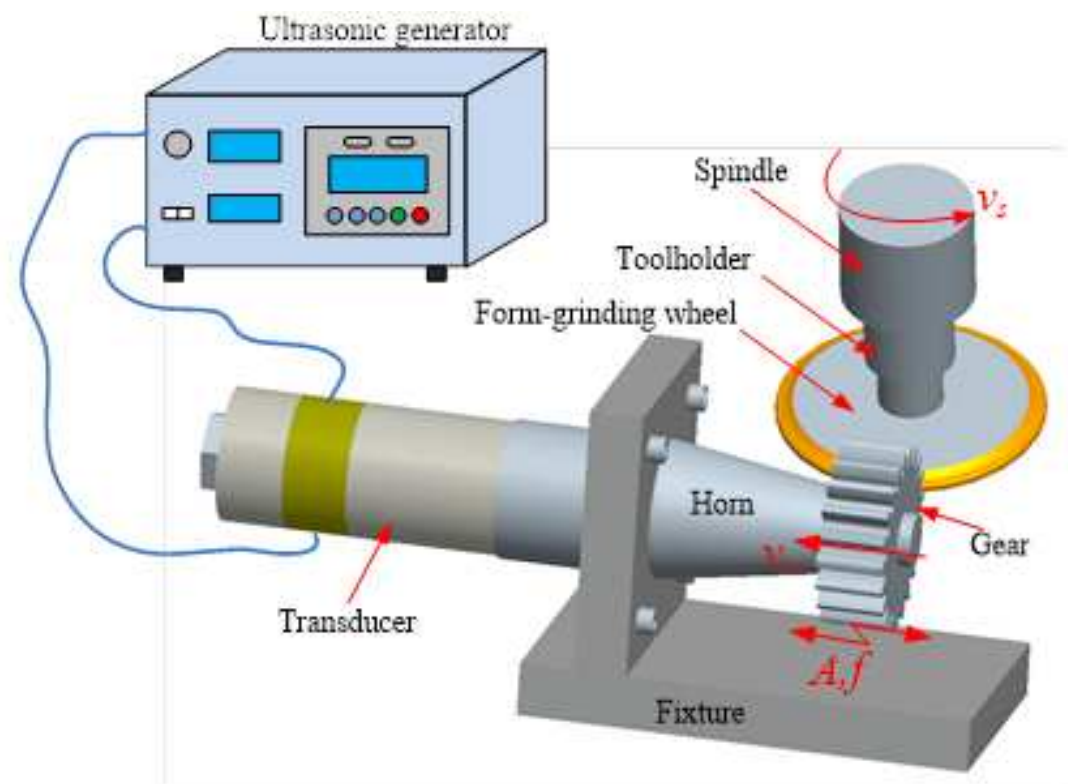

Figure 1

Schematic of tangential ultrasonic vibration-assisted grinding gear

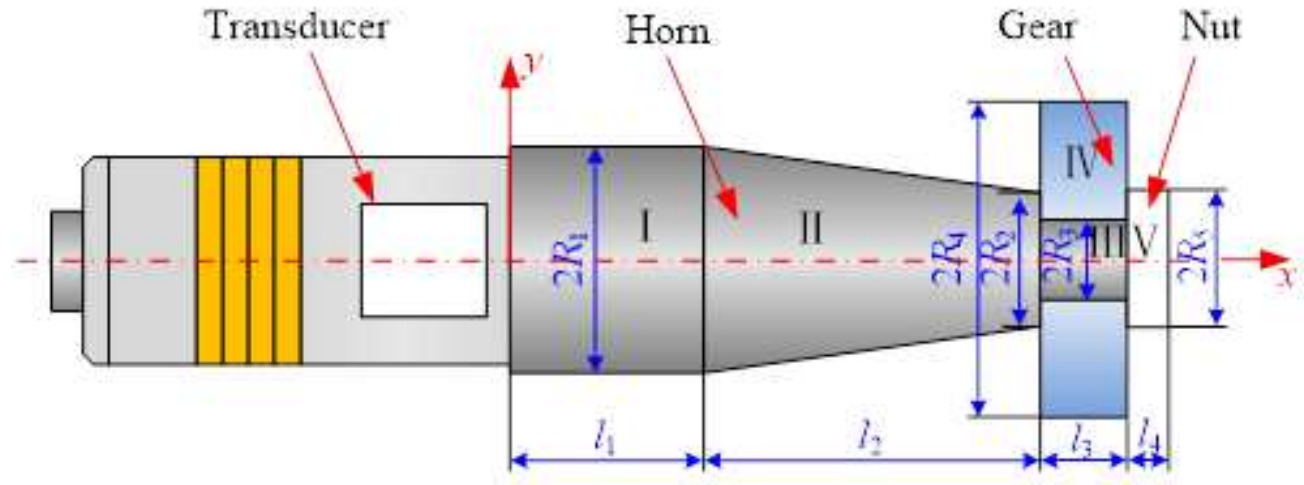

Figure 2

Longitudinal vibration system of TUVAGG 


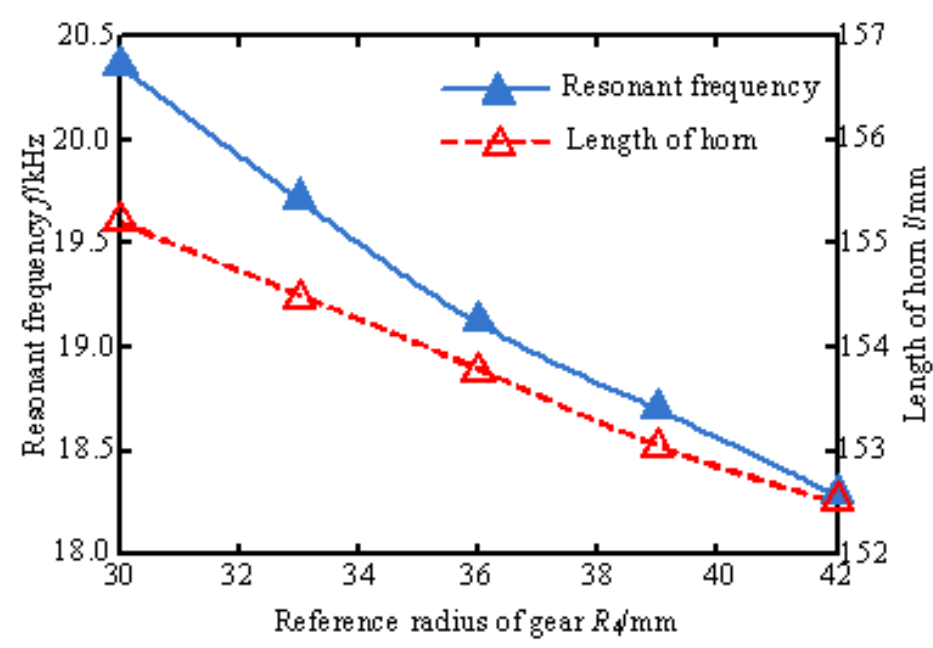

(a)

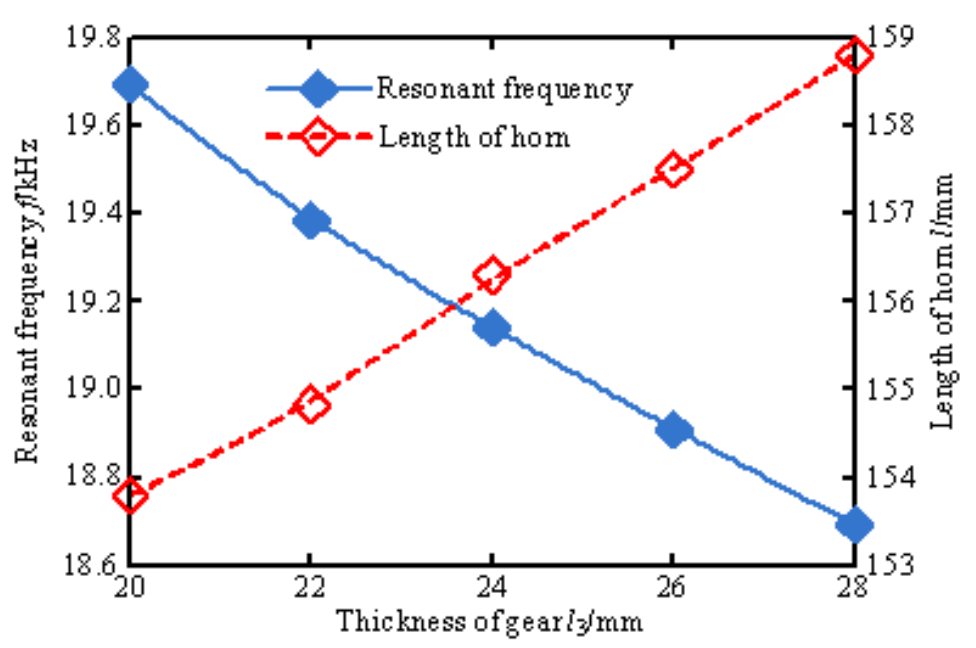

(b)

\section{Figure 3}

Influence of gear dimension on the resonant frequency and horn length (a) Reference radius (b) Thickness

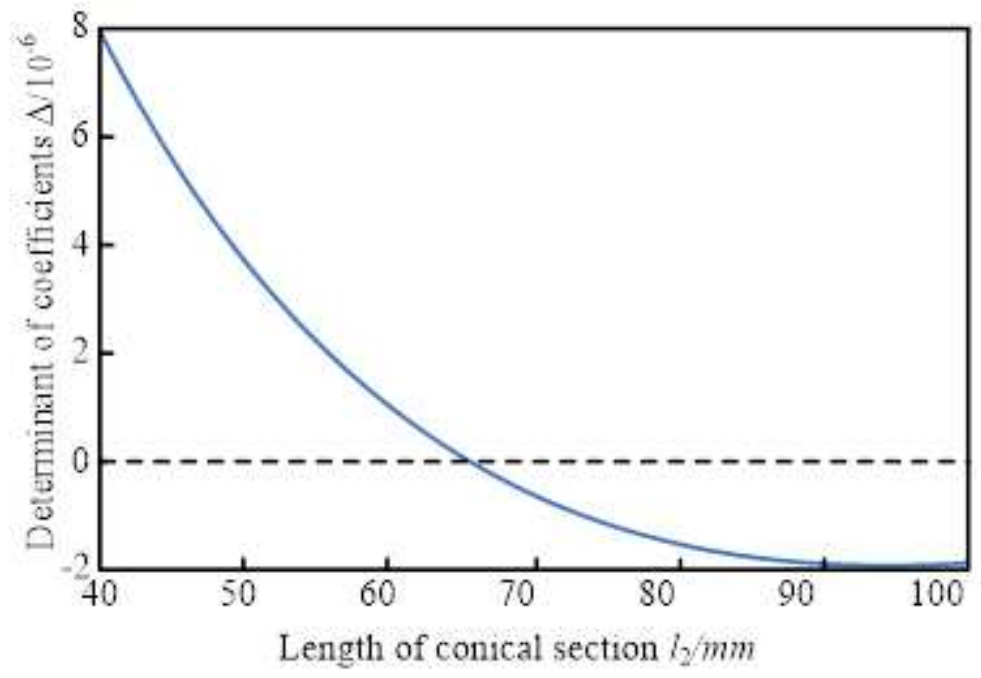

Figure 4

The solving curve of the conical length of horn 


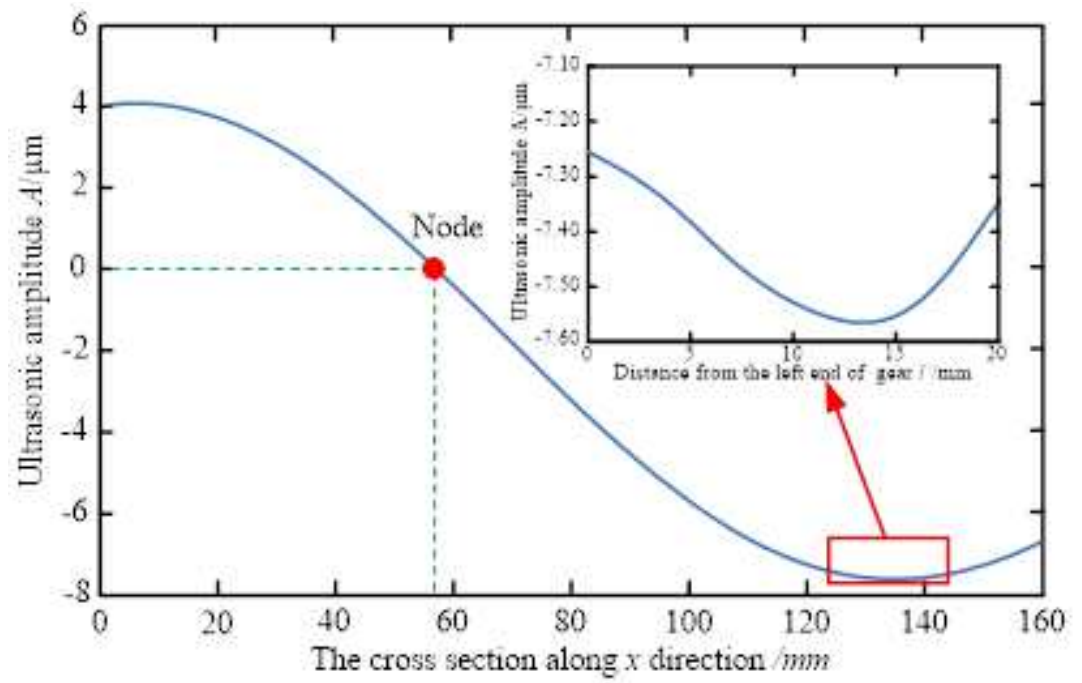

Figure 5

The ultrasonic amplitude along $\mathrm{x}$ direction

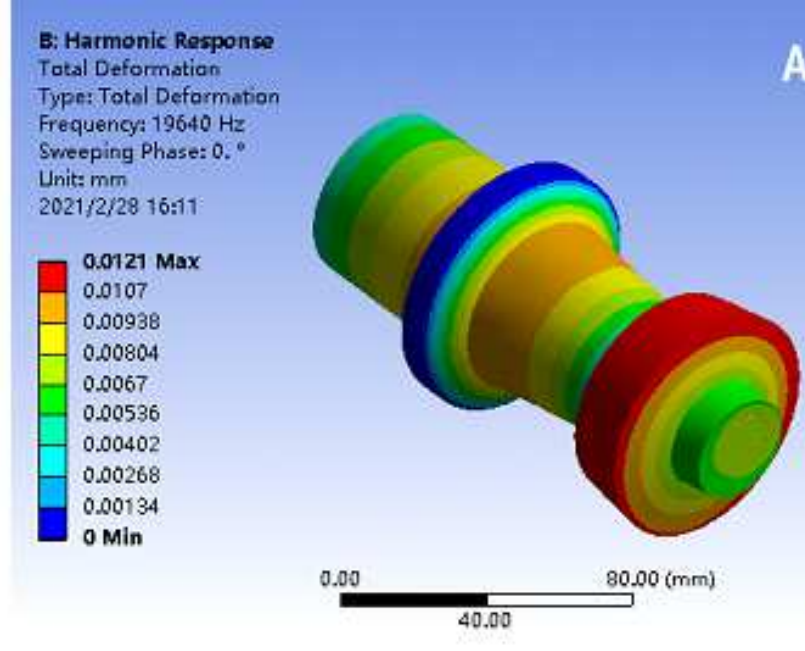

(a)

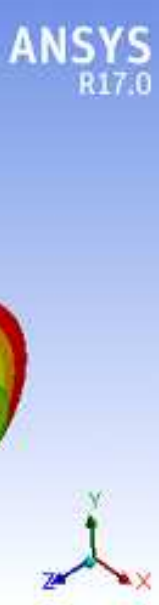

RI7:0

B: Harmonic Response

Total Defarmation:

Type: Total Deformation

Frequenga: $19200 \mathrm{~Hz}$

Sweeping Phase: $0 .{ }^{\circ}$

Unit: $\mathrm{mm}$

0.0117 Max

0.0104

0.00914

0.00783

0.00653

0.00522

0.00392

0.00261

0.00131

0 Min

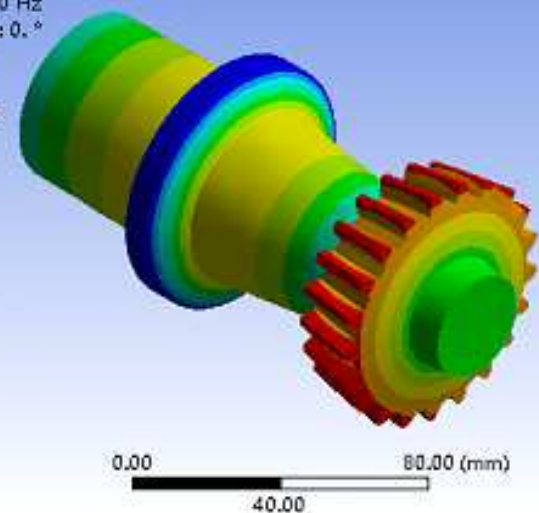

(b)

\section{ANSYS}

R17.0

\section{Figure 6}

Model of longitudinal resonance system (a) Disc vibration system (b) Gear vibration system 

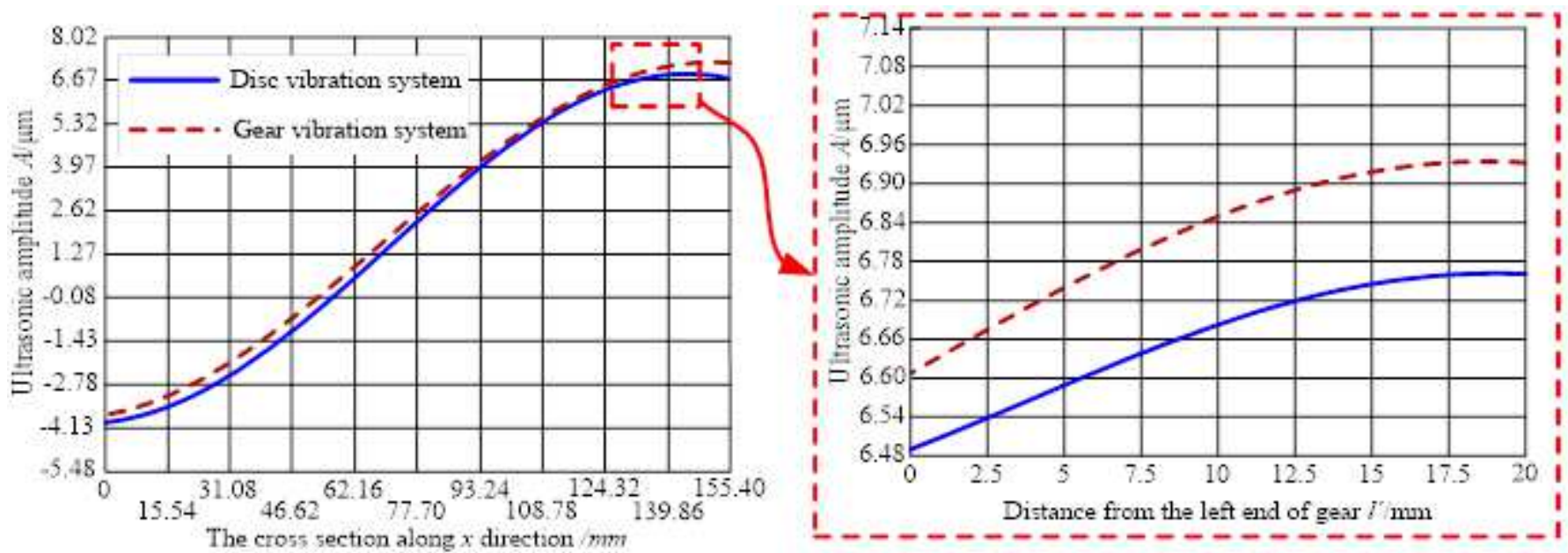

\section{Figure 7}

Distribution of ultrasonic amplitude along $\mathrm{x}$ direction

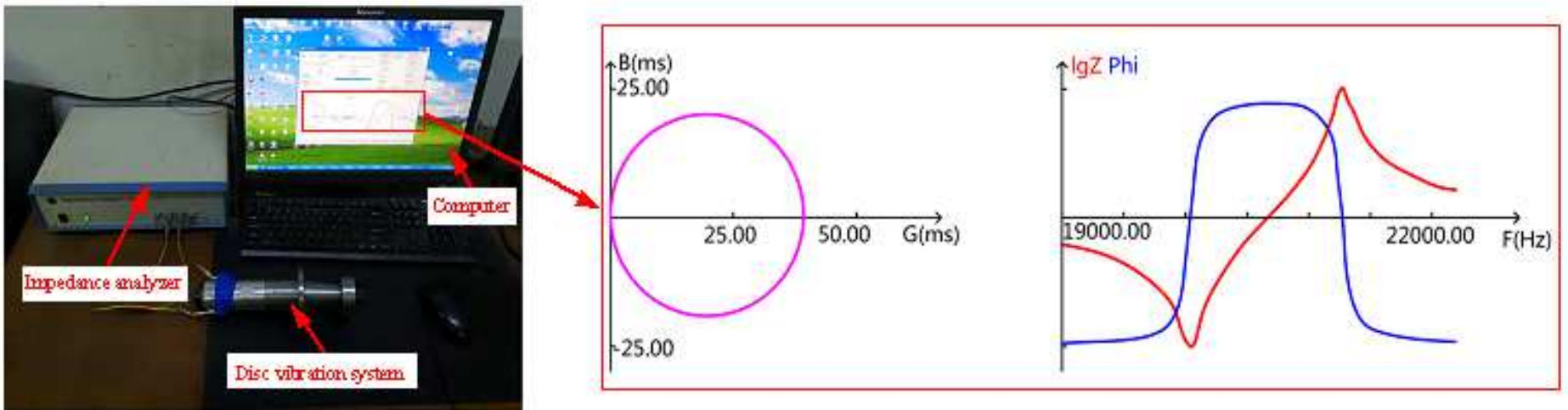

(a)
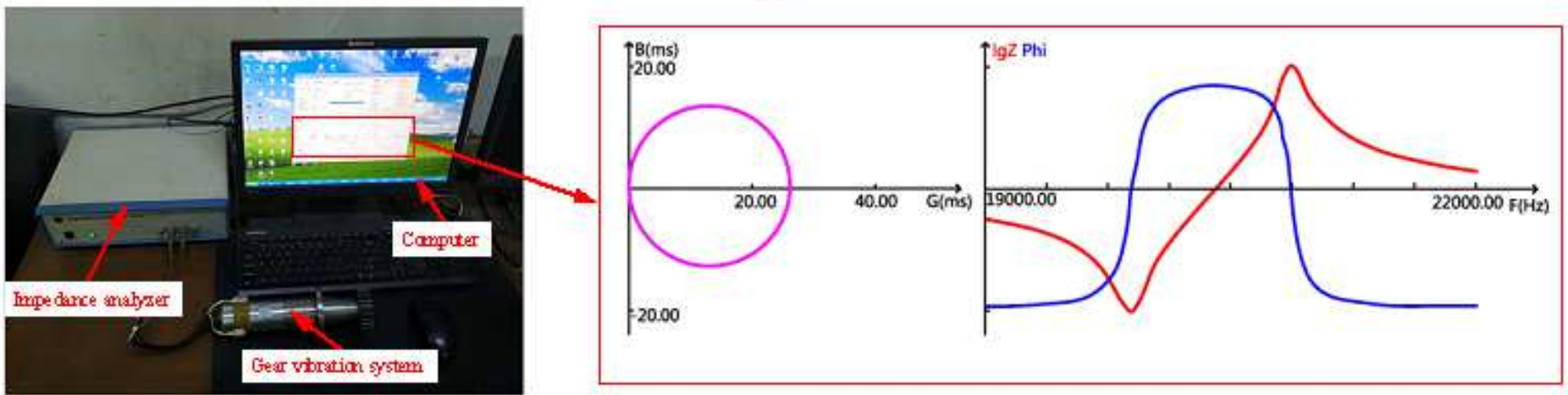

(b)

\section{Figure 8}

Impedance test of longitudinal resonance system (a) Disc vibration system (b) Gear vibration system 

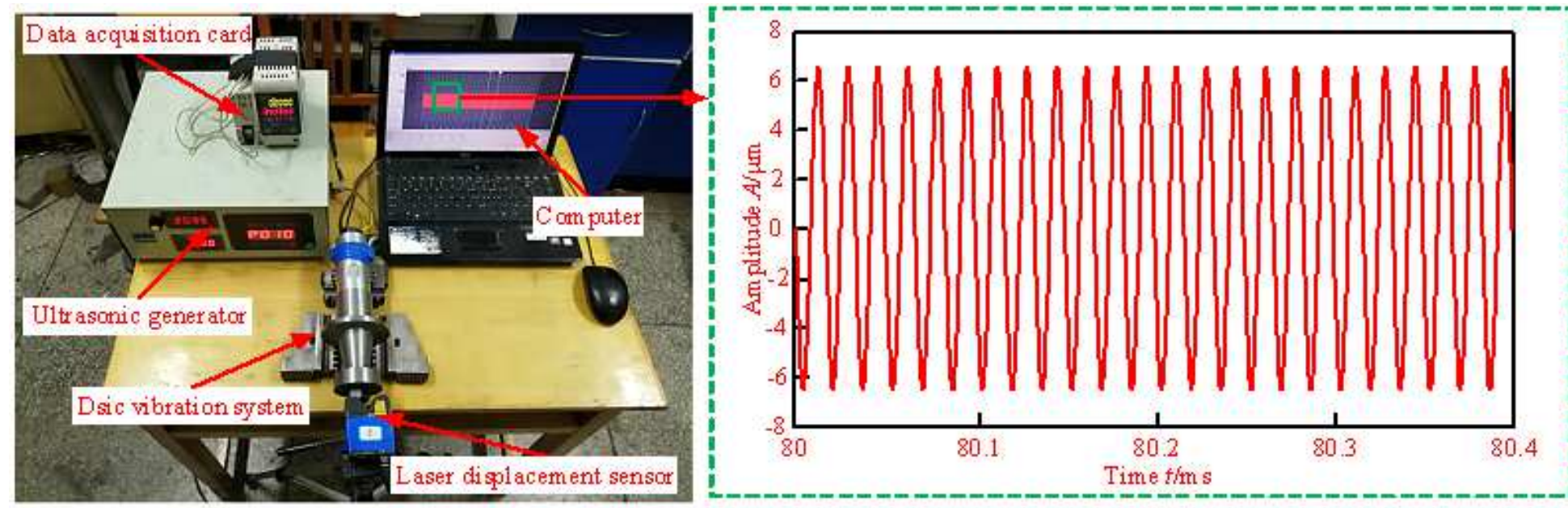

Figure 9

The ultrasonic amplitude measurement of disc vibration system

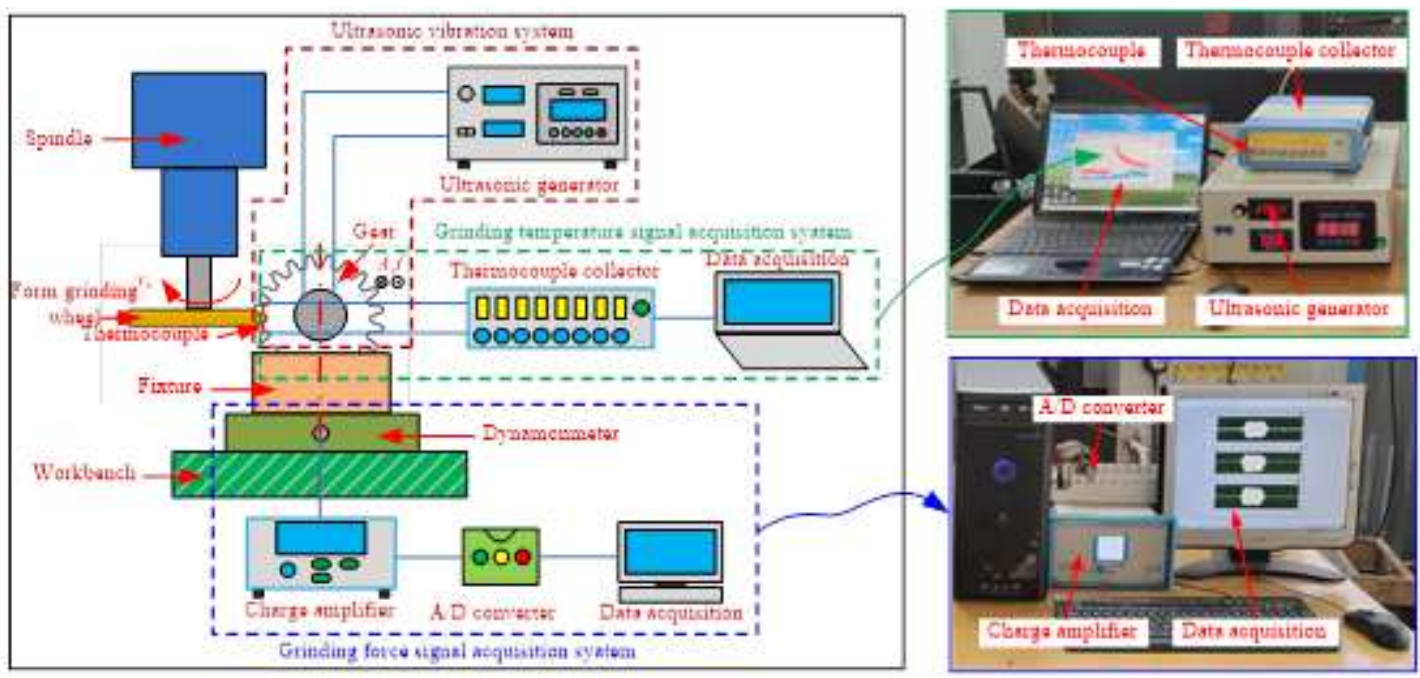

Figure 10

Experimental setup of TUVAGG

(a)

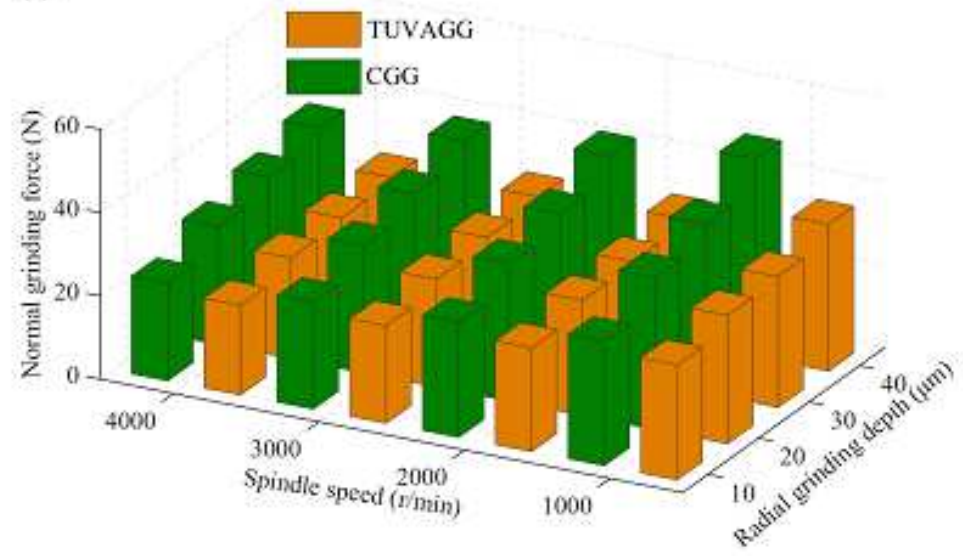

(b)

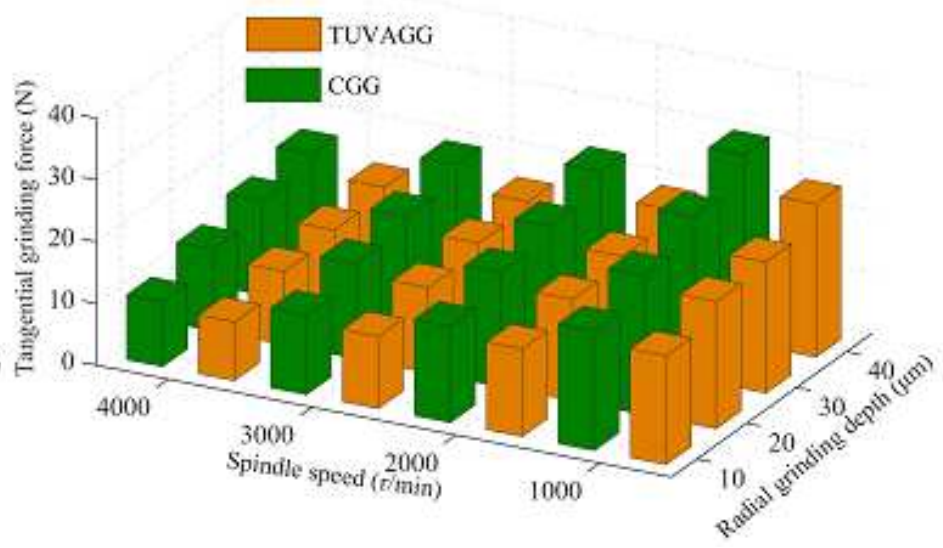

Figure 11 
Influence of grinding parameters on the grinding force (a) normal grinding force (b) tangential grinding force

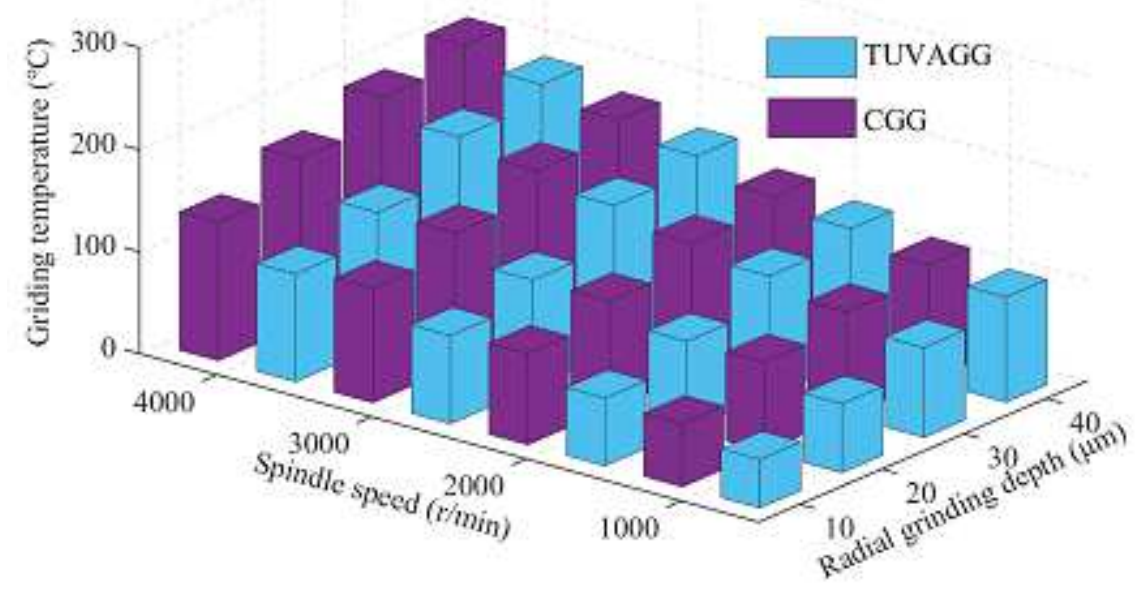

Figure 12

Relationship between the grinding temperature and grinding parameters

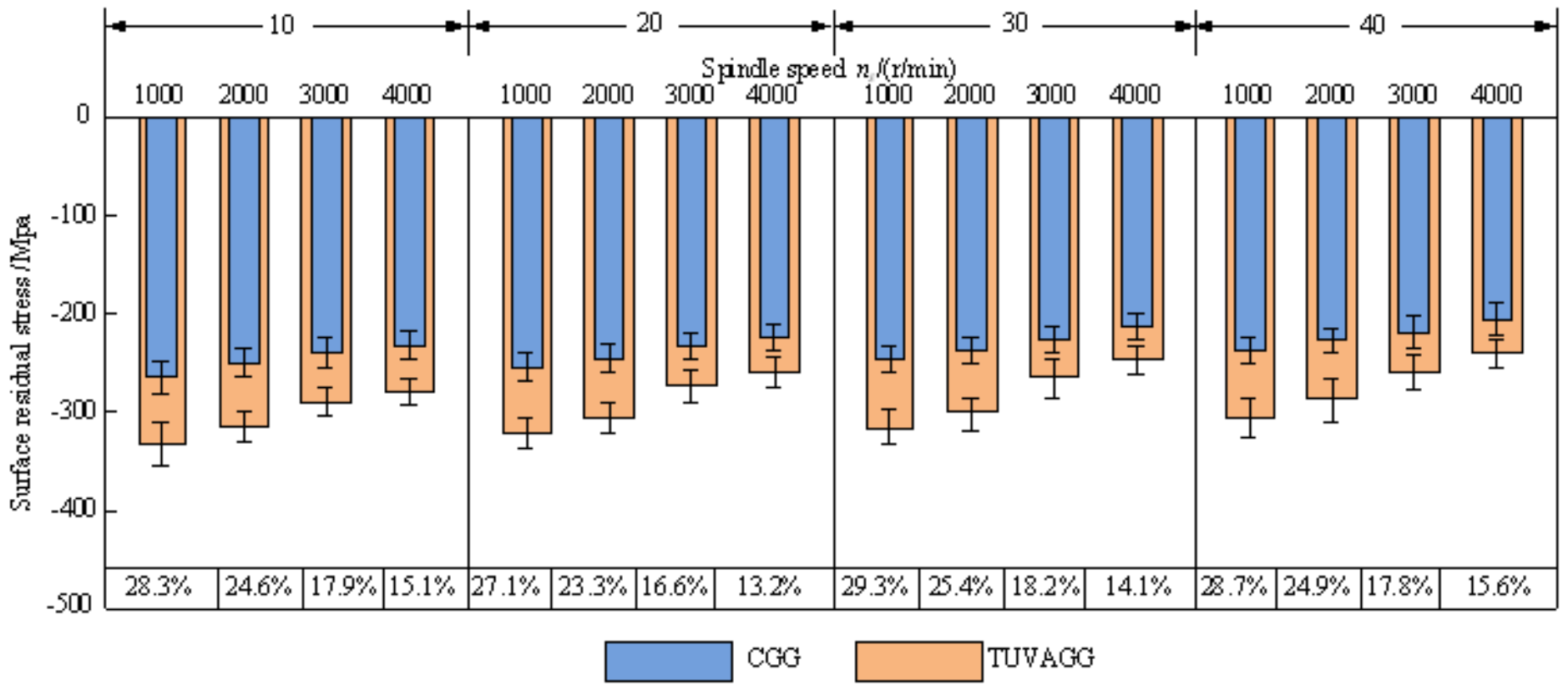

Figure 13

Trend of residual stress on tooth surface 


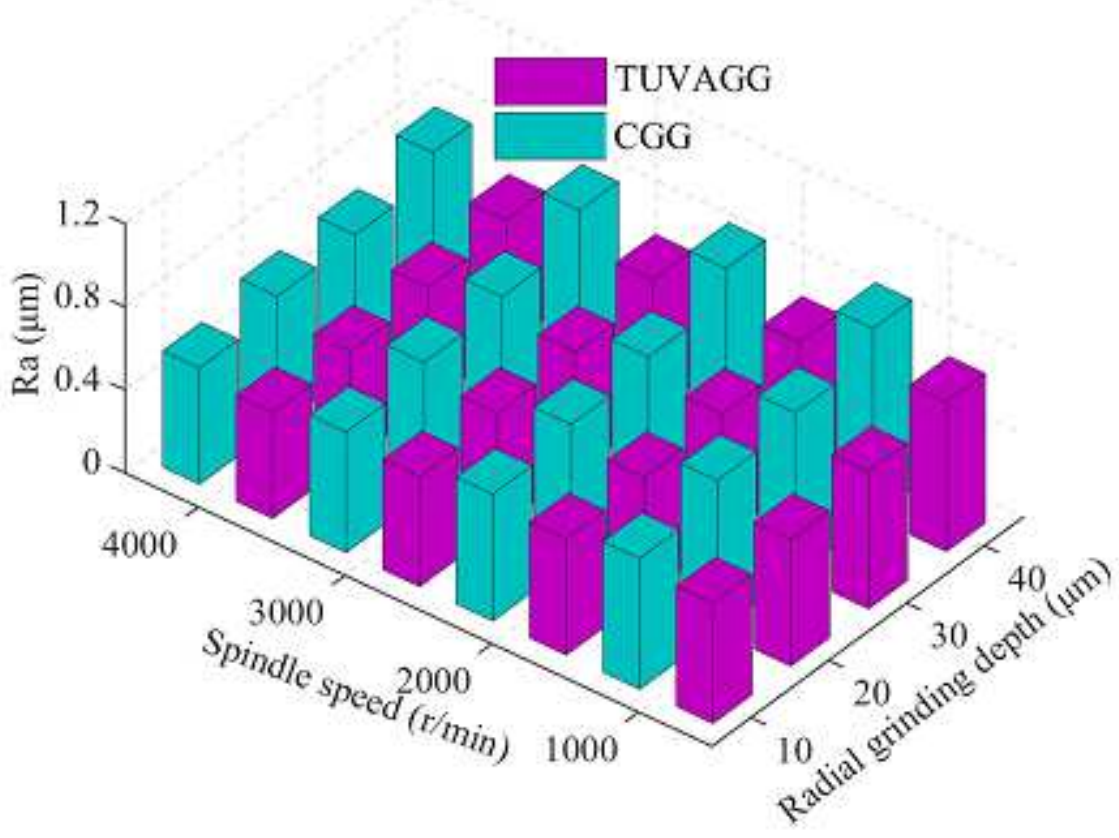

Figure 14

Relationship between the surface roughness and grinding parameters

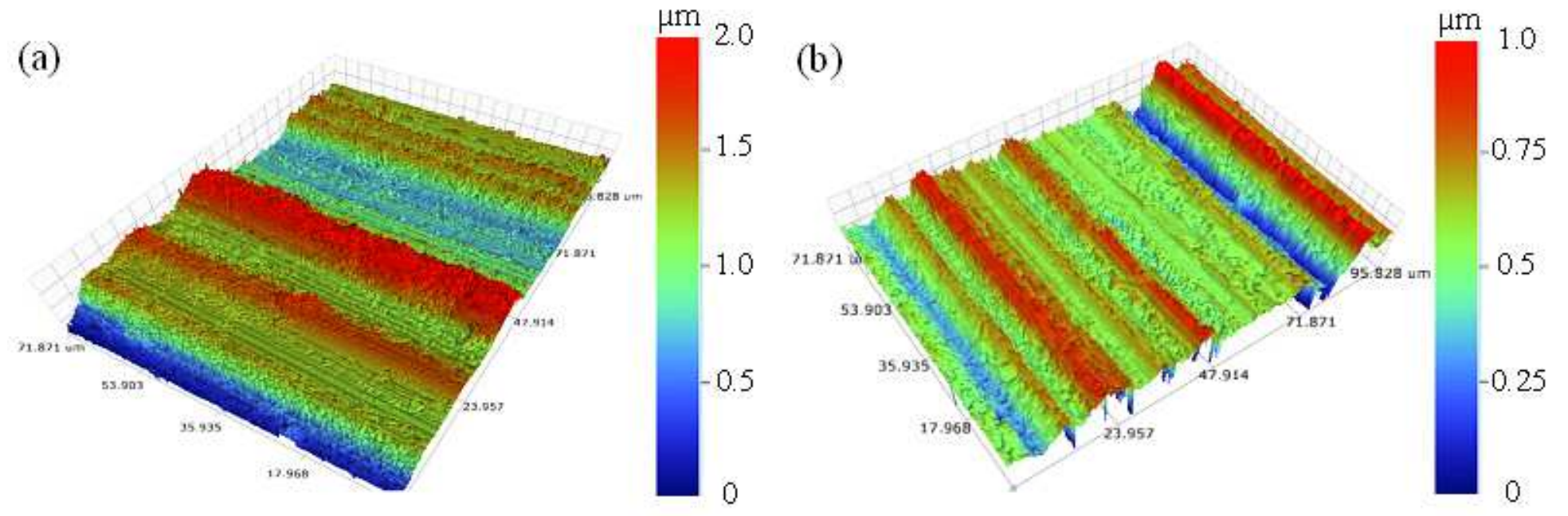

Figure 15

Tooth surface microstructure (a) CGG, (b) TUVAGG 